Summer 8-25-2019

\title{
Integument-based inferences on the swimming ability and prey hunting strategy of the bigeye thresher shark, Alopias superciliosus (Lamniformes: Alopiidae)
}

Joseph Aaron Frumkin

DePaul University, frumkinj626@gmail.com

Follow this and additional works at: https://via.library.depaul.edu/csh_etd

Part of the Biology Commons

\section{Recommended Citation}

Frumkin, Joseph Aaron, "Integument-based inferences on the swimming ability and prey hunting strategy of the bigeye thresher shark, Alopias superciliosus (Lamniformes: Alopiidae)" (2019). College of Science and Health Theses and Dissertations. 334.

https://via.library.depaul.edu/csh_etd/334

This Thesis is brought to you for free and open access by the College of Science and Health at Digital Commons@DePaul. It has been accepted for inclusion in College of Science and Health Theses and Dissertations by an authorized administrator of Digital Commons@DePaul. For more information, please contact digitalservices@depaul.edu. 
Integument-based inferences on the swimming ability and prey hunting strategy of the bigeye thresher shark, Alopias superciliosus (Lamniformes: Alopiidae)

\author{
A Thesis Presented in \\ Partial Fulfillment of \\ The Requirements for the Degree of \\ Master of Science
}

Summer 2019

By

\title{
Joseph A. Frumkin
}

Department of Biological Sciences

College of Science and Health

DePaul University

Chicago, Illinois 


\section{TABLE OF CONTENTS}

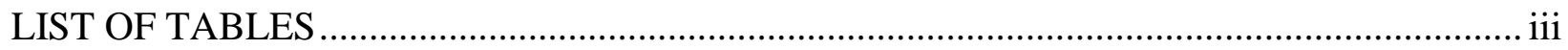

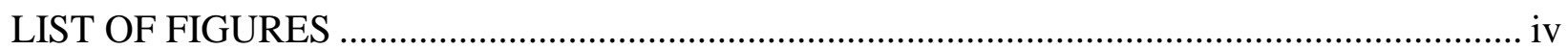

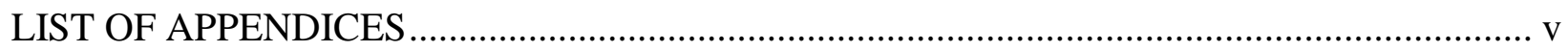

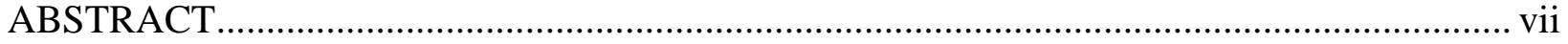

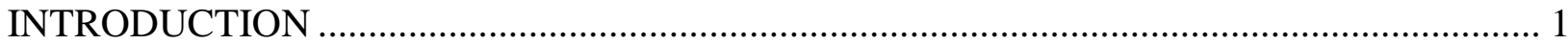

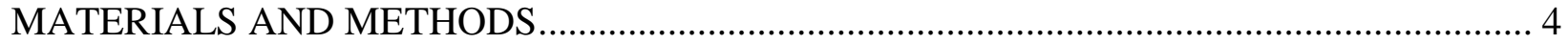

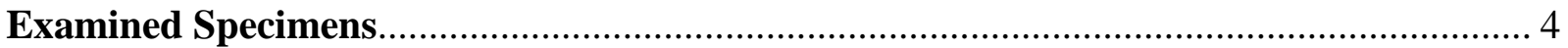

Sampling Sites and Data Collecting Methods....................................................... 7

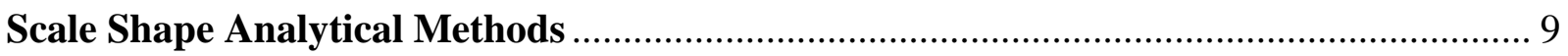

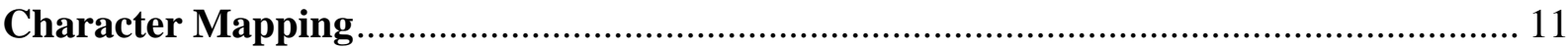

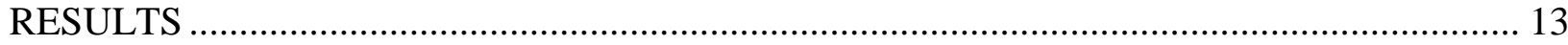

Scale Density, Interkeel Distances of Scales, and Dermis Thickness by Species ............. 13

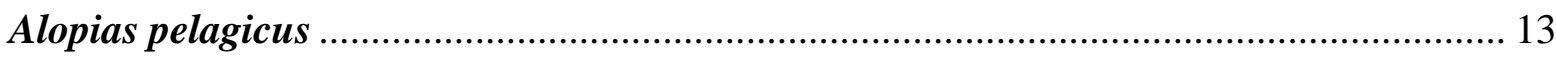

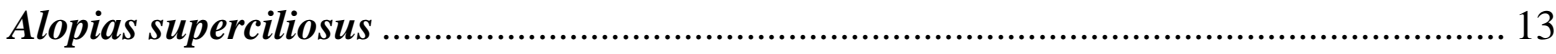

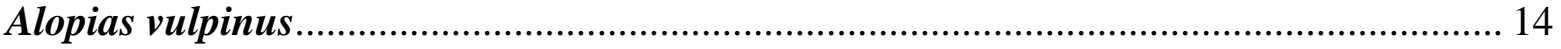

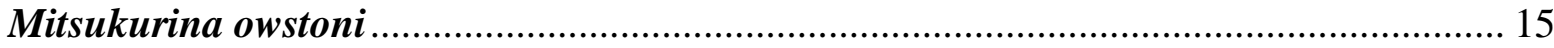

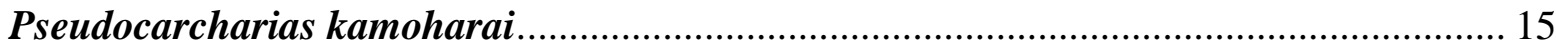

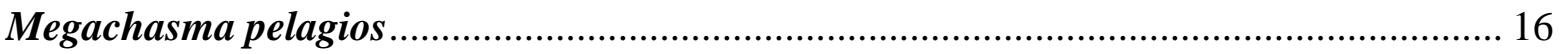

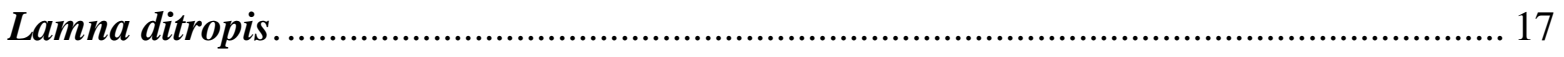

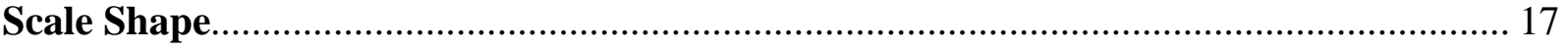

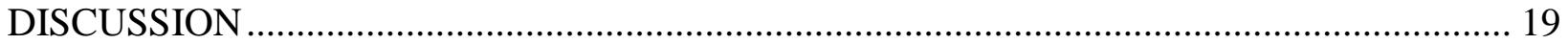

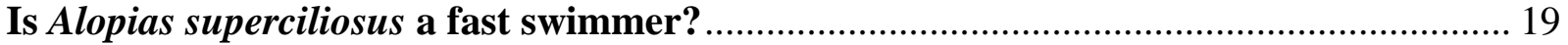

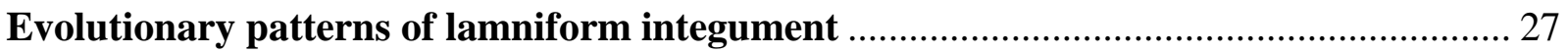

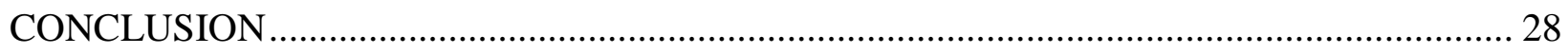

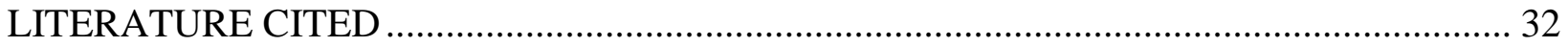




\section{LIST OF TABLES}

Table 1 Characterization of swimming speed ('fast' vs. 'slow') in this study for each lamniform

Table 2 Mahalonobis distances between scale sampling site groups with distances scaled to $100 \%$ and their respective p-values from permutations tests $(1,000$ permutation rounds)

Table 3 Mahalonobis distances between scale species groups with distances scaled to $100 \%$ and their respective $\mathrm{p}$-values from permutations tests $(1,000$ permutation rounds) 


\section{LIST OF FIGURES}

Figure 1 Extant lamniform sharks with species studied in two shades of gray

Figure 2 Integument sampling sites and examples of scanning electron micrographs of placoid scales along with morphological terminology, interkeel distance measurement, geometric morphometric landmarks, and histological examples

Figure 3 Regression analyses of total length (TL) by interkeel distances and scale densities at all sampling sites among the four examined specimens of Alopias vulpinus.

Figure 4 Scanning electron micrographs comparing morphology of placoid scales

Figure 5 Average interkeel distances, scale density, and dermis thickness measured for seven examined lamniforms

Figure 6 Graphs depicting the principle component analyses of all scale samples, and Euclidian distance dendrograms of scale shape by species and by integument sampling site

Figure 7 Graphs depicting shape variation in all scale samples grouped by species, by integument sampling site, and by sampling site and scale shape

Figure $8 \quad$ A mapping of scale density and average interkeel distance data for each species studied onto simplified molecular-based (A) and morphology-based (B) phylogenetic trees of lamniforms 


\section{LIST OF APPENDICES}

Appendix 1

Appendix 2

Appendix 3

Appendix 4

Appendix 5

Appendix 6
Raw average interkeel distance data for seven lamniform taxa examined

Raw scale density data for seven lamniform taxa examined

Raw dermis thickness data from seven lamniform taxa examined

Raw coordinate data for principle component analysis on placoid scales

Raw coordinate data for canonical variate analyses on placoid scales

grouped by integument sampling sites

Raw coordinate data for canonical variate analysis on placoid scales

grouped by species 


\section{ACKNOWLEDGEMENTS}

I would like to extend a heartfelt thanks to the following individuals who were involved in the acquisition, loan, or transportation of examined specimens: M. A. Rogers, K. Swagel, M. W. Westneat, P. Willink (FMNH); C. Klepadlo, P. A. Hastings, H. J. Walker (SIO); and L. M. Page, R. H. Robins (UF). A special thanks to B. Strack (FMNH) for her expertise in using the Scanning Electron Microscope. Without her amazing patience, I would not have had the beautiful SEM images displayed throughout this thesis. Another special thanks to the Northwestern Mouse Histology and Phenotyping Lab, especially G. E. Lord, who provided me with shark histology slides, something well out of the realm of mouse samples. Again, thanks to my committee members Drs. W. E. Aguirre and T. C. Sparkes as well as my thesis advisor, Dr. K. Shimada. Another special thanks to my graduate cohort and Shedd Aquarium coworkers, whose close kinship continued to push me to complete the project and always helped me pursue my goals and aspirations. They all provided me with advice from their fields of expertise and supported me through the entirety of this project. 


\begin{abstract}
Alopias is a group of lamniform sharks characterized by a highly elongate caudal fin with three known extant species: A. pelagicus (pelagic thresher shark), A. superciliosus (bigeye thresher shark), and A. vulpinus (common thresher shark). Alopias pelagicus and A. vulpinus are considered fast swimmers and use their caudal fin to hunt for small schooling fish by stunning them, but this feeding behavior has never been directly observed for A. superciliosus. Under the ecomorphological framework, I examined the following four integumentary variables of selected fast swimming (e.g., A. pelagicus, A. vulpinus, and Lamna) and slow swimming (e.g., Mitsukurina and Megachasma) lamniform sharks to determine whether A. superciliosus is a fast swimmer or a slow swimmer: 1) dermis thickness, 2) average interkeel distances of scales, 3) scale density, and 4) scale shape. My integumentary data indicate that A. superciliosus is a slow swimming lamniform, but it likely employs a simple laterally directed tail slap to capture its prey. Its thick dermis layer on the body indicates its extreme body bending capability, perhaps to maximize the strike power of the caudal fin in order to compensate for its slow swimming. Overall, my study points to an interpretation that $A$. superciliosus is an ambush predator, rather than an active prey-pursuing hunter. When my scale density and average interkeel distance data are mapped on to previously published molecular- and morphology-based phylogenetic trees, slow swimming is found to be a plesiomorphic condition in Lamniformes, where the evolution of fast swimming through lamniform phylogeny is more parsimonious in the morphology-based tree than the molecular-based tree. My work is the most extensive comparative study of the morphology and variation of integumentary structures, especially placoid scales, conducted so far for Lamniformes.
\end{abstract}




\section{INTRODUCTION}

For about 400 million years, elasmobranchs (sharks and rays) have diversified with unique anatomical and behavioral adaptations in aquatic environments (Moyle and Cech, 1996). One of the more studied attributes of sharks is their morphological adaptations that allow them to move with ease through water (Thomson, 1976; Thomson and Simanek, 1977; Webb, 1984; Raschi and Tabit, 1992; Gemballa et al., 2006). Swimming through water comes with many challenges, most notably high surface drag produced on moving organisms, which can lead to increased energetic costs (Helfman et al., 2009). One of the most important anatomical structures for sharks is their caudal fin that provides much of the power for swimming. All sharks possess a specialized asymmetrical caudal fin called 'heterocercal,' characterized by a large upper lobe and a small lower lobe (Thomson, 1976). Because the caudal fin has been regarded as a key anatomical structure for the evolutionary success in sharks, it has been examined from the functional kinematics (Wilga and Lauder, 2004; Lingham-Soliar, 2005; Oliver et al., 2013) and morphological (Thomson and Simanek, 1977; Kim et al., 2013) standpoints.

Another important anatomical structure that determines the swimming efficiencies in sharks is integument, notably their placoid scales and dermis (Motta, 1977; Meyer and Seegers, 2012; Tomita et al., 2014; Lauder and Di Santo, 2015). The scales cover the body of all chondrichthyans, including sharks, and have been known to assist them in a variety of functions from protection, to feeding, and especially to swimming efficiency (Reif, 1982, 1985; Raschi and Tabit, 1992; Southall and Sims, 2003). The dermis is a portion of the skin which is composed of a dense and highly coiled layer of collagen fibers, and it is generally understood that thicker dermis layers correspond to more elastic and flexible skin (Motta, 1977; Lauder and Di Santo, 
2015). Yet, still, very little is known about the morphological variation in integumentary structure and its relation to the caudal fin anatomy and behavior in sharks, including a group of sharks called Lamniformes.

Lamniformes is an order of sharks with seven living families, comprising 10 genera and 15 species (Fig. 1). They include 'fast swimming' forms such as the porbeagle and salmon shark (Lamna), mako shark (Isurus), and white shark (Carcharodon), and 'slow swimming' forms such as the goblin shark (Mitsukurina), megamouth shark (Megachasma), and basking shark (Cetorhinus) (Compagno, 2002; Castro, 2010). Alopiidae is a lamniform family with an exceptionally elongate caudal fin that is as long as the rest of the body and consists of three extant species belonging to the genus Alopias: A. pelagicus (pelagic thresher), A. superciliosus (bigeye thresher), and A. vulpinus (common thresher). Alopias pelagicus and A. vulpinus, which can reach up to 365 and $610 \mathrm{~cm}$ in total length (TL), respectively, are commonly found worldwide in tropical to cold-temperate waters and are known to actively feed on small schools of fish and squid using their caudal fin to stun prey items (Compagno, 2002; Aalbers et al., 2010; Oliver et al., 2013). On the other hand, A. superciliosus, which can reach up to $461 \mathrm{~cm} \mathrm{TL}$, is rarer compared to the other two thresher sharks (Gruber and Compagno, 1981; Compagno, 2002). Contrary to A. pelagicus and A. vulpinus, the use of the caudal fin for hunting has never been observed directly in A. superciliosus due to its preference for deeper waters (Gruber and Compagno, 1981). However, because individuals of A. superciliosus are commonly 'tail-hooked' on longline fishing gear, the species is believed to also stun its prey with its caudal fin (Stillwell and Casey, 1976; Nakano et al., 2003).

Nakano et al. (2003), using acoustic telemetry, discovered that Alopias superciliosus practice diel vertical migration, and their calculation suggested that the species may be a 
relatively slow swimmer. In contrast, Kim et al. (2013) examined the pattern of the caudal fin skeleton in lamniforms and suggested that $A$. superciliosus may be capable of fast swimming because its skeletal pattern shows characteristics reminiscent of fast swimming sharks. Under the framework of ecomorphology, which seeks to understand the morphological differences among species and how the environment may drive these functional differences (Norton et al., 1995), the aim of this present study is to determine whether A. superciliosus is a faster swimmer or a slower swimmer relative to other lamniforms, including fast swimming A. pelagicus and A. vulpinus based on integumentary structures.

Integumentary structures, notably placoid scales, of Alopias spp. have been previously illustrated or examined time to time (e.g., Welton and Farish, 1993:fig. 20; Castro, 2010:figs. 59e, 60e, 61d), and based on observed keels, Alopiidae has been generalized as a group of fast swimming sharks (Reif and Dinkelacker, 1982). In addition, integumentary structures in other lamniform species have been studied or illustrated (e.g., Castro, 2010; Motta et al., 2012; Tomita et al., 2014). However, no studies to date have systematically compared the morphology of integumentary structures among different species of lamniforms in a phylogenetic context. In this study, I specifically examine and compare the following four morphological attributes in the three species of Alopias and four other representative lamniform taxa: 1) dermis thickness, 2) interkeel distances of scales, 3) scale density, and 4) scale shape. The thickness of the dermis is examined because a thicker dermis layer is associated with greater flexibility and maneuverability of the body (Motta, 1977; Meyer and Seegers, 2012; Tomita et al., 2014; Lauder and Di Santo, 2015). Scale density and interkeel distances are examined because a greater number of scales and smaller interkeel distances are considered optimal for surface drag reduction in fast swimmers (Klimley, 2013). The shapes of scales are examined because they 
vary within each individual (Motta, 1977; Reif, 1985) and among different species in sharks (Castro, 2010) in which scales with a multi-keeled (complex) broad crown and a simple thornlike crown are considered to reflect fast swimming and slow swimming, respectively (Reif, 1982, 1985; Klimley, 2013). I predict that fast swimming lamniforms would have thick dermis, high scale density, small interkeel distances, and complex scale shape relative to lamniforms known as slow or sluggish swimmers. My study is anticipated to help deciphering the elusive behavior of $A$. superciliosus and the evolutionary pattern of integument in lamniform sharks.

\section{MATERIALS AND METHODS}

\section{Examined Specimens}

The specimens examined in this study come from the following four institutions in the United States: Scripps Institution of Oceanography (SIO), University of California at San Diego, La Jolla; Florida Museum of Natural History, University of Florida (UF), Gainesville; Field Museum of Natural History (FMNH), Chicago, Illinois; and Museum of Comparative Zoology (MCZ), Harvard University, Cambridge, Massachusetts. My samples consist of preserved specimens in ethanol and represent non-embryonic, free-swimming individuals. The specific species and specimens examined are: Alopias pelagicus ( $n=1$ : FMNH 117473, 1,690 mm TL female caught off Hawaii), A. superciliosus ( $n=1$ : UF 178509, 2,007 mm TL male caught off Florida), A. vulpinus ( $n=4$ : SIO 78-138A, 1,310 mm TL male caught off California; SIO 78-138B, 1,290 mm TL male caught off California; SIO 75-379, 1,435 mm TL male caught off California; SIO 64-804, 1,448 mm TL male caught off California), Mitsukurina owstoni (goblin shark, $n=1$ : FMNH 117742, 1,265 mm TL female caught off Japan), Pseudocarcharias 
kamoharai (crocodile shark, $n=1$ : FMNH 117474, 1,011 mm TL male caught off Hawaii), Megachasma pelagios (megamouth shark, $n=1$ : SIO 07-53, 2,149 mm TL female caught off Baja California), and Lamna ditropis (salmon shark, $n=1$ : FMNH 117475, 1,513 mm TL male caught off California) (Fig. 1; except for the three species of Alopias, all other species examined are generally referred to at the genus-level hereafter). The non-alopiid taxa included in this study were strategically selected to encompass phylogenetically basal (Mitsukurina) and derived (Lamna) forms relative to Alopias (Shimada, 2005; Naylor et al., 2012). It is worth noting that all the examined lamniform samples were roughly of similar sizes, ranging from $101 \mathrm{~cm}$ to $215 \mathrm{~cm}$ in total length (TL). The size range of all samples of Alopias is particularly narrow, spanning 127-187 cm TL. Therefore, differences in measurements arising from body size differences are considered to be small for the purposes of this study, although possible ontogenetic effects on scale data are examined in this study (see below).

Whereas swimming can be highly variable within each species with various metrics that can be applied (e.g., burst swimming, high speed swimming, and maximal swimming performance), large, highly active aquatic vertebrates are generally difficult to study under natural ecological conditions (Lowe, 2002; Lauder and Di Santo, 2015). Nevertheless, speed characterization of 'fast' or 'slow' swimming for each species examined in this study were determined based on literature (Table 1). Unless otherwise noted, the speeds listed in Table 1 are 'routine swimming speeds' (i.e., average speeds that can be aerobically maintained at relatively low energetic costs: Lauder and Di Santo, 2015), that were considered to be equivalent to Watanabe et al.'s (2015) 'cruising speeds.' For species with specific speed values in literature, I classified a 'fast' swimming shark as having a routine swimming speed of $>2.0 \mathrm{~km} \cdot \mathrm{h}^{-1}$ (Alopias vulpinus and Lamna ditropis) and 'slow' swimming sharks as any shark with a routine 
swimming speed of $\leq 2.0 \mathrm{~km} \cdot \mathrm{h}^{-1}$ (Megachasma pelagios) for the purposes of this study. Whereas contradictory speed interpretations exist for A. superciliosus (Table 1; hence one of the aims of my present study), specific swimming speed values for the following three taxa could not be found in literature: Alopias pelagicus, Mitsukurina, and Pseudocarcharias. Alopias pelagicus is generally characterized as an 'active strong swimmer' capable of repeated leaping (breaching) (Compagno, 2002; Ebert et al., 2013), and video footage of its hunting behavior indicates fast swimming (Oliver et al., 2013). Based on Oliver et al.'s (2013, fig. 5) depiction, even the early stage (specifically frames 3-7 in the illustration) of its tail-slapping hunting motion generated by the rotation of the caudal fin over the head as the forward-moving momentum of the body comes to a sudden stop is calculated to be already at least $16 \mathrm{~km} \cdot \mathrm{h}^{-1}$ in speed, suggesting that it is not unreasonable to assume A. pelagicus is a fast swimmer (Table 1). On the other hand, by contrasting it with 'swift' lamnid sharks, Nakaya et al. (2016, pp. 6-8) described Mitsukurina to have "flabby body musculature, small and soft fins, and a weak ribbon-like caudal fin" and noted it to "swim slowly by undulating the tail region and long caudal fin" based on their in situ observations; thus, Mitsukurina is classified as a slow swimmer (Table 1). The swimming mode or speed of Pseudocarcharias has never been documented in literature. Where it has simply been inferred to be a 'strong active swimmer' (Compagno, 2002; Ebert et al., 2013), the skeletal pattern of its caudal fin is reminiscent of slow swimming lamniforms (Kim et al., 2013). Because of the conflicting interpretations similar to the case with A. superciliosus (Table 1), I chose to also include Pseudocarcharias in this study to gain additional insight into its swimming ability. In summary, A. pelagicus, A. vulpinus, and L. ditropis are here considered to be fast swimmers, Mitsukurina and Megachasma slow swimmers, and A. superciliosus and Pseudocarcharias taxa of uncertain swimming ability. 


\section{Sampling Sites and Data Collecting Methods}

Approximately $1-\mathrm{cm}^{2}$ patches of scale-covered skin samples (but deep enough to include part of the underlying muscular tissue) were taken from four different regions on each shark specimen: one sample from the body and three samples along the upper lobe of the caudal fin. The sample from the body is taken from the lateral side of the body between the dorsal fin and one of the pectoral fins. For the three samples from the caudal fin, the length of the caudal fin was measured for each shark specimen from the caudal peduncle to the terminal end of the upper lobe, and a skin patch was removed using a scalpel at $0 \%, 45 \%$, and $90 \%$ of the length of the upper lobe. The four integument sampling sites are here referred to as SS-B (for site on the body), SS-0, SS-45, and SS-90 (for three sites on the caudal fin), respectively (Fig. 2A). Each sample was then divided into two smaller pieces, one for the morphological analysis of placoid scales (e.g., Fig. 2B, C) and the other for histological preparation (e.g., Fig. 2D-G).

For the analysis of dermis thicknesses, collected skin samples (see above) underwent histological preparation at the Mouse Histology and Phenotyping Laboratory at Northwestern University at Chicago, Illinois. Each sample was sliced through perpendicular to the skin surface, including the placoid scales, to reveal the cross-sectional view of the dermis. The standard Hemtoxylin and Eosin (H\&E) staining protocol (Luna, 1968) was used for each sample to enhance microstructure. For each specimen of Alopias, two histological slides were prepared to compare the dermis thickness at SS-B and SS-45 (e.g., Fig. 2D-G). In the other four lamniform taxa, only SS-45 histological samples were prepared. All specimens were examined using a Nikon Eclipse Ts2 Inverted Routine Microscope and were imaged at 4x magnification. For the purposes of this study, the two sublayers of the dermis, stratum laxum and stratum compactum 
(Motta et al., 2012), were not distinguished from one another, and the total dermis thickness for all samples were measured using Image J imaging software (Schneider et al., 2012).

For the morphological analysis of placoid scales, images were generated at FMNH using a LEO Zeiss 1550 Scanning Electron Microscope. Each skin sample was placed on a pin mount, attached using a carbon adhesive patch, and coated with gold to better increase image quality (Fourie, 1982). Two images were generated for each sample. The first image was taken at 60x magnification with a viewing area of $2 \mathrm{~mm} \times 1.5 \mathrm{~mm}$ for scale density and interkeel distance data (Fig. 2C). Using Image J (Schneider et al., 2012), each 60x magnification image had a grid overlaid on top of it and nine points were chosen at equidistant locations. The scales closest to each of the nine points were selected for interkeel distance data. I measured the distance between the central keel and its closest dorsal keel (Fig. 2C) in each of the nine scales, and an average of the nine measurements was then taken and recorded. For scale density data, all fully intact scales within the viewing area were counted. The second image was taken at 300x magnification (Fig. 2B) for the scale shape analysis (see below).

Previous research and texts (e.g., Reif, 1982; Raschi and Muscik, 1986; Klimley, 2013; Cooper et al., 2018) have not explicitly alluded to the possible presence of ontogenetic or sexual variation in the morphology or size of placoid scales. However, I examined the possible ontogenetic effect on the average interkeel distance and scale density that may be present in Alopias vulpinus in which multiple samples $(n=4)$ were available. The four samples were all males and thus sex-based variation could not be evaluated. I used each measurement taken from each of the four integument sampling sites (Fig. 2A) and performed a regression between each scale variable and TL among the four specimens (Fig. 3). It is important to note that none of the morphological features seems to be significantly affected by growth. Although there seems to be 
a slight positive correlation within the majority of my scale density data (slopes at $-0.158,0.132$, 0.164 , and 0.340 ), it is hard to support that these patterns are due to ontogenetic effects on scale morphological features $\left(r^{2}\right.$ range $\left.0.08-0.57\right)$. Although it seems to be a field that needs more attention, research suggests that in general, my morphological features are not affected by ontogeny.

\section{Scale Shape Analytical Methods}

For the analysis of scale shape, a two-dimensional geometric morphometrics approach was used. Geometric morphometrics attempts to describe shape variation through the use of coordinate data (Zelditch et al., 2012; Adams et al., 2013). It is particularly useful when attempting to use statistical analyses and description to ascertain shape variation within and among samples (Rohlf, 1998). In my study, only the posterior half of the scales was examined due to some scales having their anterior half obscured by other overlapping scales in the image. Whereas morphological differences of scales among sampling sites and among taxa appear to be more pronounced in the posterior half of the scale compared to its anterior half, similar approaches have been used to examine the geometric morphometrics of partially exposed shapes (e.g., Jiang et al., 2016). Using the program TpsDig2 (Rohlf, 1998), three landmarks were chosen as definitive local anatomical features common across scale samples among all the examined species: Landmark 1, the dorsal-most point on the posterior margin; Landmark 2, the posterior-

most point on the central keel; and Landmark 3, the ventral-most point on the posterior margin (Fig. 2C). Fourteen equidistant semi-landmarks, 28 in total, were then placed between Landmarks 1 and 2, and between Landmarks 2 and 3 to ensure that reliable tangents were computed along the curved shape of each scale (Gunz and Mitteroecker, 2013). Due to the 
arbitrary spacing of these semi-landmarks, the sliding method was used to minimize the procrustes distance of the semi-landmarks relative to the average shape of the entire scale (Fig. 2C).

A generalized Procrustes analysis that superimposes the configurations of landmarks from all scales onto a common coordinate plane was used. Through using a least squares method, all scales were translated to the origin, rotated, and scaled to the same size to generate a set of shape variables. Using the program TpsRelw (Rohlf, 1998), the raw coordinate data from my landmarks were used for the relative warp analysis, or the principle component analysis (PCA), of these shape variables. PCA attempts to find deformations within the examined shape and builds a scatterplot to represent shape variation in tangent space (Adams et al., 2013).

With the averages from my raw PCA data, I calculated Euclidian distances and generated dendrograms of relatedness within each integument sampling site and each species. All dendrograms were calculated using the program PAST (Paleontological Statistics) from Hammer et al. (2001) which adapted the simple Euclidian distance methods from Sokal (1958). My Euclidian distance dendrogram is a simple clustering method that involves using Unweighted Pair Group Method with Arithmetic Means (UPGMA). A basic cluster analyses such as this can partition the objects of analyses within the data (i.e., integument sampling site and species) through a multidimensional analytical method. A dendrogram is then generated which can graphically depict hierarchical clustering within the data. The "branches" of my dendrograms meet at "nodes" which visually fuse at the similarity index of the branches. Length of branches and connectedness give no indication to relatedness and can be "swiveled" without affecting the information conveyed by the dendrograms (Legendre and Legendre, 2012). 
Using the program MorphoJ (Klingenberg, 2011), a canonical variate analysis (CVA) was used to determine the differences in shape between two separate groups: 1) variation in scale shape by sampling site and 2) variation in scale shape by species. Whereas PCA is a useful technique that constructs variables that can examine variation among individuals, CVA is useful in this study because it constructs variables that describe relative differences between groups which can be specified, such as the difference in scale shape when comparing among sampling sites or comparing among species. In this study, I used a simple approach to discriminate among my CV groups using Mahalanobis distances, which are calculated by measuring the distance of a specimen from the group mean. Each distance is adjusted by the pattern of covariation within the group. It measures how different shape data of a single point are from a group mean of shape data (Zelditch et al., 2012), or the differences among my sampling sites when grouped by species and sampling site, giving me an amount that quantifies how different each point is from another group.

\section{Character Mapping}

Character mapping (e.g., Harvey and Pagel, 1991; Kim et al., 2013) was used to examine the evolutionary pattern of scale morphology within Lamniformes. The scale density and average interkeel distances data were mapped for each of the seven lamniform species on previously proposed morphology-based (Compagno, 1990) and molecular-based (Martin et al., 2002) phylogenetic trees. Although a number of phylogenetic studies that included lamniforms are known (e.g., Shirai, 1996; Naylor et al., 1997; Shimada, 2005; Human et al., 2006; Heinicke et al., 2009; Vélez-Zuazo and Agnarsson, 2011; Naylor et al., 2012), I chose Compagno (1990) and Martin et al.'s (2002) trees because they included all lamniform genera with the most well- 
resolved depiction of their interrelationships. However, it is worth pointing out that the tree topology of other morphology-based studies (e.g., Shirai, 1996; Shimada, 2005) overall do not contradict that of Compagno's (1990) tree, particularly in regards to the systematic position of Alopias with respect to other lamniforms especially Mitsukurina, Megachasma, and Lamna. Likewise, the tree topology attained by other molecular-based studies generally agrees with the tree topology seen in Martin et al.'s (2002) tree. In addition, it should also be noted that Compagno's (1990) morphology-based tree is free of integument-based characters; therefore, mapping of integument-based measurements is independent of how the phylogenetic tree was constructed in the first place, as for the molecular-based tree.

For the purpose of this study, the phylogenetic trees were simplified to include only the seven lamniform taxa examined. A few molecular studies have shown the non-monophyly of Alopias where A. superciliosus fell outside of the Alopias clade (e.g., Vélez-Zuazo and Agnarsson, 2011; Naylor et al., 2012:fig. 2.2), but the three species are generally accepted to constitute a monophyletic group (e.g., Compagno, 1990; Shimada, 2005; Human et al., 2006; Naylor et al., 2012:45). Although A. pelagicus and A. vulpinus are likely sister species (e.g., Shimada, 2005; Human et al., 2006; Vélez-Zuazo and Agnarsson, 2011; Naylor et al., 2012), the three Alopias spp. are grouped as an unresolved polytomy because Compagno (1990) showed a sister relationship between A. pelagicus and A. superciliosus, and because the aim of my character mapping is to examine a large-scale (intergeneric) evolutionary pattern in the integument of Lamniformes. 


\section{RESULTS}

\section{Scale Density, Interkeel Distances of Scales, and Dermis Thickness by Species}

Alopias pelagicus - In general, scales of A. pelagicus have a more squared teardrop shape that becomes rounder towards the distal tip of the caudal fin (Fig. 4A). Scales at SS-B have three longitudinal keels defining two valleys. All keels extend posteriorly and remain relatively even in length. The average interkeel distance at SS-B is $41 \mu \mathrm{m}$ with scale density of 132 scales per $2 \mathrm{~mm} \times 1.5 \mathrm{~mm}$ area (Appendices 1,2). The scale density is relatively high but patches of skin are slightly visible around the base of many scales at SS-B. Scales near the caudal peduncle (SS-0) have an extended central keel compared to those at SS-B, but the dorsal and ventral keels extend progressively and the posterior edge of each scale becomes more rounded along the caudal fin posteriorly based on scales at SS-45 and SS-90. In general, scales on the caudal fin (SS-0, SS-45, and SS-90) first possess three keels with two valleys and progress to five keels with four valleys (Figs. 4A, 5A, B). The average interkeel distances is $38 \mu \mathrm{m}$ at SS$0,34 \mu \mathrm{m}$ at SS-45, and $27 \mu \mathrm{m}$ at SS-90, showing a decreasing trend within the caudal fin posteriorly. Scale densities are about 184 scales at SS-0, 155 scales at SS-45, and 214 scales at SS-90 for each $2 \mathrm{~mm} \times 1.5 \mathrm{~mm}$ area. Alopias pelagicus has a similar body dermis thickness to $A$. vulpinus (Fig. 5C) at about $353 \mu \mathrm{m}$ (Fig. 2D) and a caudal fin dermis thickness of about $305 \mu \mathrm{m}$ (Fig. 2E; Appendix 3).

Alopias superciliosus - In general, the shape of the scales in this species is triangular and dagger shaped (Fig. 4B). Scales at SS-B have a single, sharp, central keel with dorsal and ventral keels extensively reduced. The average interkeel distance at SS-B is $56 \mu \mathrm{m}$ with a scale density of 52 scales per $2 \mathrm{~mm} \times 1.5 \mathrm{~mm}$ area (Appendices 1,2 ). The scale density is relatively low and 
patches of skin are highly visible around the base of many scales at SS-B. Scales near the caudal peduncle (SS-0) continue to have an extended central keel, but the dorsal and ventral keels are more prominent compared to scales at SS-B, with scales becoming flatter and more heavily ridged at SS-90. In general, the number of keels on the scales of the caudal fin (SS-0, SS-45, and SS-90) increases posteriorly from three keels with two valleys to five keels with four valleys (Figs. 4B, 5A, B). The average interkeel distances on scales is $37 \mu \mathrm{m}$ at SS-0, $33 \mu \mathrm{m}$ at SS-45, and $27 \mu \mathrm{m}$ at SS-90, showing a decreasing trend within the caudal fin posteriorly. In contrast, scale densities, in general, show an increasing trend in which they are about 135 scales at SS-0, 201 scales at SS-45, and 276 scales at SS-90 for each $2 \mathrm{~mm} \times 1.5 \mathrm{~mm}$ area. Alopias superciliosus has the most conspicuous of the dermis thickness data, with the largest body dermis thickness

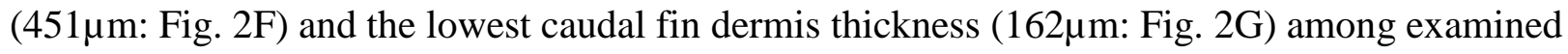
lamniforms (Fig. 5C; Appendix 3).

Alopias vulpinus - In general, scales of A. vulpinus has a tear-dropped shape (Fig. 4C). Scales at SS-B have three longitudinal keels defining two valleys. All keels extend posteriorly, but the central keel extends the farthest. The interkeel distances range from about $45-51 \mu \mathrm{m}$ with an average of $47.94 \mu \mathrm{m}$. The scale density at SS-B ranges 72-119 scales per $2 \mathrm{~mm} \times 1.5 \mathrm{~mm}$ area with an average count of 98 scales (Appendices 1,2). The scale density is relatively low and patches of skin are visible around the base of many scales at SS-B. Scales near the caudal peduncle (SS-0) are similar in morphology to those at SS-B, but the central keel progressively becomes shorter and the posterior edge of each scale becomes more rounded along the caudal fin posteriorly based on scales at SS-45 and SS-90. In general, scales on the caudal fin (SS-0, SS-45, and SS-90) possess five keels with four valleys (Figs. 4C, 5A, B). The average interkeel distances on scales is $45 \mu \mathrm{m}$ at SS- $0,36 \mu \mathrm{m}$ at SS- 45 , and $31 \mu \mathrm{m}$ at SS-90, showing a decreasing 
trend within the caudal fin posteriorly. In contrast, scale densities show an increasing trend in which they are about 110 scales at SS-0, 172 scales at SS-45, and 214 scales at SS-90 in each 2 $\mathrm{mm} \times 1.5 \mathrm{~mm}$ area. Among the seven lamniform species examined, A. vulpinus has the highest dermis thicknesses both in the body (about $383 \mu \mathrm{m}$ ) and caudal fin (about $473 \mu \mathrm{m}$ ) (Fig. 5C; Appendix 3).

Mitsukurina owstoni - In general, scales of M. owstoni have a circular spiked shape (Fig. 4D). Scales at SS-B have no distinct central keel, are more rounded, and spiked. The average interkeel distance at SS-B is $67 \mu \mathrm{m}$ with a scale density of 13 scales in a $2 \mathrm{~mm} \times 1.5 \mathrm{~mm}$ area. The scale density is low and scales are large in comparison to the three species of Alopias, with patches of skin visible around the base of all scales at SS-B. Scales near the caudal peduncle (SS0) continue to remain rounded and spiked, but the central keel becomes more prominent as the scale becomes flatter and more streamlined along the skin compared to scales at SS-B. In general, scales on the caudal fin (SS-0, SS-45, and SS-90) possess one central keel with two valleys on either side (Figs. 4D, 5A, B). The average interkeel distance on scales is $61 \mu \mathrm{m}$ at SS$0,63 \mu \mathrm{m}$ at SS-45, and $54 \mu \mathrm{m}$ at SS-90, showing a slight posteriorly decreasing trend within the caudal fin (Appendix 1). Scale density, in general, show a decreasing trend in which they are about 21 scales at SS-0, 16 scales at SS-45, and 16 scales at SS-90 for each $2 \mathrm{~mm} \times 1.5 \mathrm{~mm}$ area (Appendix 2). Among the seven lamniform species examined, M. owstoni has the third thinnest caudal fin dermis thickness at $240 \mu \mathrm{m}$ (Fig. 5C; Appendix 3).

Pseudocarcharias kamoharai-In general, scales of Pseudocarcharias have an arrowhead shape that is consistent across the shark (Fig. 4E). Scales at SS-B have an extended central keel with dorsal and ventral keels present. The average interkeel distance at SS-B is 80 $\mu \mathrm{m}$ with scale density of 47 scales in a $2 \mathrm{~mm} \times 1.5 \mathrm{~mm}$ area (Appendices 1,2 ). The scale density 
is relatively low and scales are large in comparison to the three species of Alopias with patches of skin visible around the base of many scales at SS-B. Scales near the caudal peduncle (SS-0) continue to have an extended central keel, but the dorsal and ventral keels become more elongated, making scales more triangular compared to scales at SS-B. In general, scales on the caudal fin (SS-0, SS-45, and SS-90) possess three keels with two valleys (Figs. 4E, 5A, B). The average interkeel distances on scales is $71 \mu \mathrm{m}$ at SS-0, $59 \mu \mathrm{m}$ at SS- 45 , and $59 \mu \mathrm{m}$ at SS-90, showing a slight decreasing trend within the caudal fin posteriorly. In contrast, scale densities, in general, show an increasing trend in which they are about 58 scales at SS-0, 72 scales at SS-45, and 68 scales at SS-90 for each $2 \mathrm{~mm} \times 1.5 \mathrm{~mm}$ area. Pseudocarcharias has a caudal fin dermis thickness of only $157 \mu \mathrm{m}$ that is closest to that in A. superciliosus (Fig. 5C; Appendix 3).

Megachasma pelagios - In general, scales of Megachasma have a more triangular teardrop shape (Fig. 4F). Scales at SS-B have a central keel that extends well past the dorsal and ventral keels. The average interkeel distance at SS-B is $107 \mu \mathrm{m}$ with 27 scales in a $2 \mathrm{~mm} \times 1.5$ $\mathrm{mm}$ area (Appendices 1,2). The scale density is low and scales are large in comparison to the three species of Alopias with patches of skin visible around the base of most scales at SS-B. Scales near the caudal peduncle (SS-0) retain a similar shape with the dorsal and ventral keels extending and scales decreasing in size compared to scales at SS-B. In general, scales on the caudal fin (SS-0, SS-45, and SS-90) possess three keels with two valleys (Figs. 4F, 5A, B). The average interkeel distance on scales is $98 \mu \mathrm{m}$ at SS-0, $84 \mu \mathrm{m}$ at SS-45, and $70 \mu \mathrm{m}$ at SS-90, showing a decreasing trend within the caudal fin posteriorly. Overall scale densities show an increasing trend in which they are about 50 scales at SS-0, 34 scales at SS- 45 , and 58 scales at SS-90 for each $2 \mathrm{~mm} \times 1.5 \mathrm{~mm}$ area. Megachasma shares a similar caudal fin dermis thickness to Mitsukurina, measuring $263 \mu \mathrm{m}$ (Fig. 5C; Appendix 3). 
Lamna ditropis - In general, scales of $L$. ditropis become more rounded towards the distal end of the caudal fin (Fig. 4G). Scales at SS-B have a central keel that is even in length with the dorsal and ventral keels. In this species, the average interkeel distance at SS-B is $82 \mu \mathrm{m}$ with 72 scales per $2 \mathrm{~mm} \times 1.5 \mathrm{~mm}$ area, the largest scale density among the examined nonAlopias sharks. The scale density is high and scales are large in comparison to the three species of Alopias with no skin patches visible around any scales at SS-B. Scales near the caudal peduncle (SS-0) retain a similar shape with a slightly more extended central keel and the increased prominence of dorsal and lateral keels compared to scales at SS-B. In general, scales on the caudal fin (SS-0, SS-45, and SS-90) possess five keels with four valleys (Figs. 4G, 5A, B). The average interkeel distance on scales is $77 \mu \mathrm{m}$ at SS-0, $72 \mu \mathrm{m}$ at SS- 45 , and $50 \mu \mathrm{m}$ at SS90, showing a posteriorly decreasing trend within the caudal fin. Scale densities, in general, show an increasing trend in which they are about 55 scales at SS-0, 49 scales at SS-45, and 82 scales at SS-90 for each $2 \mathrm{~mm} \times 1.5 \mathrm{~mm}$ area (Appendices 1,2). The dermis thickness at SS-45 in Lamna, that measures about $342 \mu \mathrm{m}$, is similar to the dermis thickness at SS-B in A. pelagicus (Fig. 5C; Appendix 3).

\section{Scale Shape}

Appendix 4 shows my raw coordinate data from PCA. PCA shows that the first two principal component axes account for $65.39 \%$ of the variation in placoid scale shapes. Principal components 1 (PC1), 2 (PC2), and 3 (PC3) account for 49.36\%, 16.03\%, and 13.36\% of variation, respectively. Due to the close variation between PC2 and PC3, two separate graphs were generated to examine their relationships with PC1 (Fig. 6A, B). In both graphs, species clumped in distinct groups. Alopias pelagicus and A. vulpinus are centrally located, whereas 
those of Lamna has low scores on PC1. Mitsukurina is located in the positive quadrants of PC1 and variable in scale shape along PC2. Megachasma is confined to the lower limits of PC2 with very little variation along PC1 in which they are tightly clustered and do not overlap with any other species; however, Megachasma overlap considerably with A. vulpinus and A. pelagicus when plotted against PC1 and PC3. Mitsukurina slightly overlaps with A. superciliosus; however, when plotted against PC1 and PC3, the vertical range of the plots of Mitsukurina is drastically reduced, resulting in greater overlap with Alopias spp. In both sets of PCA, A. superciliosus considerably overlap with those of multiple taxa including A. vulpinus, Mitsukurina, and Megachasma. Along PC1, the shape of the placoid scales changes by an elongation of their posterior tip and a thinning of the dorsal and ventral exterior margins. Along PC2, although less variation is observed, the placoid scales generally extend in width along the anteroposterior axis.

Euclidian distance dendrograms using UPGMA reveal distance relationships found in the PCA (Fig. 6C, D). The species with the least distance between them are Alopias superciliosus paired with Pseudocarcharias, which has a slightly lower distance index than A. vulpinus paired with A. pelagicus (Fig. 6C). Mitsukurina had the farthest distance index from all other examined lamniform taxa. For scale sampling sites, the dendrogram revealed a small distance index between SS-45 and SS-90 on the caudal fin (Fig. 6D). The next farthest distance index grouped all caudal fin scales (SS-0, SS-45, and SS-90) into one cluster, with the body scales (SS-B) having the greatest distance index from all other integument sampling sites (Fig. 6C, D).

Appendices 5 and 6 show my raw coordinate data from CVA. CVA reveals that CV1 and CV2 account for $65.05 \%$ and $19.78 \%$ of the variation found among integument sampling sites and $58.85 \%$ and $27.12 \%$ of the variation found among species, respectively. Both sets of CVA 
(Fig. 7A, B) reveal significant differences among all sampling sites and among species

(Mahalanobis distance: $\mathrm{p}<<0.0001$ for sampling site; $\mathrm{p}<0.05$ for species: Tables 2,3 ). For sampling sites, the CV1 axis separates the scale shape variation found between SS-90 scales and the other three sampling sites (SS-B, SS-0, and SS-45). The CV2 separates SS-B, SS-0, and SS45; however, there is greater overlap between plots of SS-B and SS-45 scales than either those of SS-B or SS-45 scales with SS-0 scales. For species, the CV1 axis separates scale shape variation found between 'fast' and 'slow' swimmers. Whereas CV2 represents the spread of scale shape variation among slow swimmers, it seems that there is far less spread in scale shape variation among fast swimmers. Due to the high variation within CV1 found in both of my analyses, one by species and another by sampling sites, I combined these two axes to form one analysis examining shape variation when species and sampling sites were considered together (Fig. 7C). The sampling site plots show a similar pattern, with SS-B, SS-0, and SS-45 clumping near the positive coordinates of my sampling site axis (X-axis), whereas plots of SS-90 are all tightly clustered in the negative ranges. Similarly, the species axis (Y-axis) shows patterns of fast swimmers being confined towards the positive end and slow swimmers being clumped near the negative ranges of the axis.

\section{DISCUSSION}

\section{Is Alopias superciliosus a fast swimmer?}

Nakano et al. (2003) conducted acoustic telemetry to track the movement of two individuals of Alopias superciliosus in the eastern Pacific Ocean for 70-96 hours and found very distinct diel vertical migration patterns where they spent in the shallow (80-130 m) water during 
the night and deep (200-500 m) water during the day. In addition, they calculated the estimated mean swimming speed of A. superciliosus to be $1.3-2.0 \mathrm{~km} \cdot \mathrm{h}^{-1}$, which can be characterized as slow swimming, similar to Megachasma $\left(1.5 \mathrm{~km} \cdot \mathrm{h}^{-1}\right.$ : see Nelson et al., 1997), and slower than $A$. vulpinus $\left(2.1 \mathrm{~km} \cdot \mathrm{h}^{-1}\right.$ : Cartamil et al., 2010) and members of Lamnidae $\left(4.2 \mathrm{~km} \cdot \mathrm{h}^{-1}\right.$ for Lamna nasus: Saunders et al., 2011; $3.9 \mathrm{~km} \cdot \mathrm{h}^{-1}$ for L. ditropis: Watanabe et al., 2015 ; up to $4.4 \mathrm{~km} \cdot \mathrm{h}^{-1}$ for Isurus: Holts and Bedford, 1993; and $3.2 \mathrm{~km} \cdot \mathrm{h}^{-1}$ for Carcharodon: Strong et al., 1992). Subsequently, Kim et al. (2013) examined the organization of the caudal fin skeleton in all 15 extant species of lamniforms (Fig. 1) and found that, despite its highly elongate upper lobe, the caudal fin of $A$. superciliosus showed the same skeletal pattern as fast swimming sharks. Therefore, Kim et al.’s (2013) results are at odds with Nakano et al.'s (2003) data. My present study examines integumentary structures of A. superciliosus and its lamniform relatives that include fast swimming (A. pelagicus, A. vulpinus, and Lamna) and slow swimming (Mitsukurina and Megachasma) forms to assess the swimming ability of A. superciliosus.

Ridges and valleys present on placoid scales assist in surface drag reduction because they decrease micro-turbulence caused by small water eddies as water flows over a ridged surface (Bechert et al., 1985; Reif, 1985; Raschi and Tabit, 1992; Lang et al., 2014; Afroz et al., 2016; Du Clos et al., 2018). In general, smaller interkeel distances of placoid scales are ideal for optimal surface drag reduction (Reif and Dinkelacker, 1982; Reif, 1985; Klimley, 2013). Thus, I predicted that fast swimming lamniforms should possess small interkeel distances (see Introduction). My data show that the average interkeel distances (Fig. 5A) are wider in the scales on the body (SS-B) than those near the terminal end of their caudal fins (SS-45 and SS-90) regardless of taxa, meaning that scale-based surface drag reduction is greater on the caudal fin than on the body. When Alopias spp. are compared to other examined lamniforms, the ranges of 
average interkeel distances in Alopias spp. are generally much smaller (Fig. 5A), indicating the specialization of Alopias within Lamniformes. Among the three species of Alopias, the ranges of average interkeel distances are small, and the ranges of caudal fin data practically overlap. One notable observation is that the average interkeel distance of SS-B in A. superciliosus is conspicuously large and occurs separated from the plots of Alopias spp. (Fig. 5A). However, the large interkeel distance is deceptive, because scales at SS-B in A. superciliosus are characterized by anteroposteriorly short, but rather thorn-like crowns, that are suited for protective function (e.g., against predators and ectoparsites) rather than swimming efficiency (Reif, 1982). These observations suggest that $A$. superciliosus is a slower swimmer than A. pelagicus and A. vulpinus but can move its caudal fin as efficiently as A. pelagicus and A. vulpinus. Deceptively high interkeel distances are also found in thorn-like scales at all the sampling sites in Mitsukurina (Fig. 4D), characteristic of scales more suited for protection rather than swimming efficiency. In contrast, the average interkeel distances are overall the greatest in Megachasma in my dataset (Fig. 5A), which is expected of a slow swimming shark. This observation, in turn, supports that slow swimming can be achieved without thorn-like scales, but instead with broadly-keeled scales. The interkeel distances in Lamna are found to be similar to, although slightly less than, those of Pseudocarcharias (Fig. 5A), indicating that Pseudocarcharias could indeed be a 'strong active swimmer' (Compagno, 2002; Ebert et al., 2013; but see also below).

A greater number of placoid scales per unit area, especially combined with scales with smaller interkeel distances, is said to also reduce surface drag (Klimley, 2013). Therefore, I predicted that fast swimming sharks should exhibit high scale densities (see Introduction). My data suggest that the average scale densities vary widely within the family Alopiidae, whereas the disparity in scale density is small within the other lamniforms (Fig. 5B). In the scale density 
data for Alopias vulpinus, standard deviations from body to caudal fin ranges 50-250 scales per 2 $\mathrm{mm} \times 1.5 \mathrm{~mm}$ viewing area, which makes it difficult to make a definitive conclusion as to the role scale density plays in swimming speed, however, patterns in scale density are still observable. The body (SS-B) has the lowest scale density, whereas the highest density is found towards the terminal end of the caudal fin (SS-90). The disparity is particularly high for $A$. superciliosus where the scale densities in its caudal fin are comparable to, or even higher than, those in the caudal fin of A. pelagicus and A. vulpinus. The scale density at SS-B for $A$. superciliosus is comparable to that of the body scales for Pseudocarcharias and Lamna. Scale density, particularly at SS-B, is lowest in the slow swimming lamniform, Mitsukurina. In the other three non-Alopias species, close overlap among all sampling sites makes scale density differences difficult to discern from each other; however, their scale densities are all quite low, compared to the family Alopiidae. In summary, my scale density data patterns (Fig. 5B) suggest that a high density in scales towards the terminal end of the caudal fin, as well as the variation in scale density within the family Alopiidae, are unique attributes compared to other lamniforms. The biological significance of this variation may be to assist with surface drag reduction of the caudal fin or perhaps smaller scales, thus higher scale density, allows for greater flexibility of the caudal fin during hunting. The surface drag of the caudal fin in A. superciliosus is inferred to be comparable to, or more reduced than, that in A. pelagicus and A. vulpinus. However, patterns based on the low scale density in SS-B suggest that A. superciliosus is the slowest swimmer among Alopias spp.

In sharks, a thicker dermis layer is associated with greater flexibility and maneuverability of the body (Motta, 1977; Meyer and Seegers, 2012; Tomita et al., 2014; Lauder and Di Santo, 2015). The body and caudal fin of A. pelagicus and A. vulpinus undergo extreme bending to 
execute their rapid tail slapping behavior (Aalbers et al., 2010; Oliver et al., 2013). Therefore, these fast swimming Alopias spp. are predicted to possess a thick dermis relative to slow swimming lamniforms (see Introduction). In my study, histological samples were taken from SSB and SS-45 for the three species of Alopias, whereas SS-45 was the only sampling site for the four non-Alopias lamniforms examined (Fig. 5C). The exact significance of the dermis thickness at SS-45 in the non-Alopias lamniforms is unclear without samples from SS-B. However, strikingly, dermis thicknesses between the two sampling sites (SS-B and SS-45) are exceptionally different in A. superciliosus, unlike A. pelagicus and A. vulpinus that have similar dermis thicknesses between the two sampling sites (Fig. 5C; see also Fig. 2D-G). This result indicates that $A$. superciliosus has a flexible body like A. pelagicus and A. vulpinus, but its caudal fin is interpreted to be considerably 'stiff' with no extreme bending capability. These dermal thickness data are consistent with tactile of the caudal fin of each examined sample of Alopias spp. through palpation, where the caudal fin of A. superciliosus lacks substantial flexibility observed in the caudal fin of A. pelagicus and A. vulpinus (JAF, personal observation). Therefore, the observed stiffness of the caudal fin in the sample of A. superciliosus is interpreted to be largely biological, and due not simply to postmortem artificial effects from preservatives.

Placoid scales that have a broad crown with multiple keels are commonly found in fast swimming sharks, whereas those with a simple thorn-like crown are typically found in slow swimmers (Reif, 1982, 1985; Klimley, 2013). My quantitative analyses on the shapes of placoid scales using PCA show that the scale shapes of Alopias superciliosus are overall more similar to Mitsukurina, Pseudocarcharias, and Megachasma (i.e., plots largely clustered in the right half of Figure 6A, B) than to A. pelagicus, A. vulpinus, and Lamna (i.e., plots largely clustered in the left half of Figure 6A, B). My Euclidian distance dendrogram by sampling sites shows closer 
similarities in scale shape towards the terminal end of the caudal fin from the body (Fig. 6C).Also, my dendrogram by taxa indicates that the scale shapes of Mitsukurina are quite different from the rest of the six lamniform taxa examined (Fig. 6D), reflecting the unique thornlike form in Mitsukurina (Fig. 4D). Nevertheless, A. superciliosus is clustered closely with Megachasma (and Pseudocarcharias) and distinctively separated from A. pelagicus, A. vulpinus, and Lamna. Therefore, my PCA-based scale shape examination suggests that $A$. superciliosus and Pseudocarcharias are slow swimmers.

I used CVA to assess the scale shape variation quantitatively. My CVA scatter plot diagram of taxa (Fig. 7A) clearly discriminates the plots of fast swimming lamniforms $(A$. pelagicus, A. vulpinus, and Lamna; i.e., samples in the right half of the graph) from those of slow swimmers (Mitsukurina and Megachasma: i.e., samples in the left half of the graph). A. superciliosus (and Pseudocarcharias) are clustered closely with the slow swimming lamniforms. My CVA scatter plot diagram of integument sampling sites (Fig. 7B) reveals that, generally, scale shapes can be discriminated among different sampling sites regardless of taxa, where most of the plots of SS-B and those of SS-90 occur on the opposite ends of the graph. When the discriminant analysis is grouped by sampling sites and taxa (Fig. 7C), the same location-based pattern of plots along the CV1-axis in Figure 7B is discernable. More importantly, the graph clearly discriminates plots of fast swimmers (i.e., plots on the upper half) from those of slow swimmers (i.e., plots on the bottom half). Again, plots of $A$. superciliosus (and Pseudocarcharias) are clustered closely with the slow swimming lamniforms, Mitsukurina and Megachasma.

The primary diet of A. vulpinus and A. pelagicus is a diverse array of schooling prey items, with a heavy emphasis on anchovies (Engrulidae) (Preti et al., 2004) along with others 
such as herring, sardines, shad, pichards, menhaden (Clupeidae), needlefish (Belonidae), mackerels (Scombridae), bluefishes (Pomatorridae), and lanternfishes (Myctophidae) (Preti et al., 2001; Compagno, 2002). The tail-slapping hunting method, where the terminal end of the caudal fin swings over the head as the forward motion of the body comes to a sudden stop, employed by A. pelagicus and A. vulpinus, is particularly ideal for hunting schooling fish, because it maximizes the probability of stunning more than one fish per strike (Oliver et al., 2013). In addition, high scale densities found in all three species of Alopias is perhaps to accommodate abrasion during its complex tail-slapping movement during hunting (Reif, 1982; Compagno, 2002; Castro, 2010; Meyer and Seegers, 2012; this study). On the other hand, $A$. superciliosus feeds mainly on squids and a variety of pelagic teleost fishes, many of which are larger solitary prey, such as lancetfishes (Alepisauridae), mackerel (Scombridae), small billfishes (Isiophoridae), and hake (Merluccidae) (Gruber and Compagno, 1981). Because captured individuals of A. superciliosus are also commonly tail-hooked, the species most likely uses its caudal fin for pray capturing (Stillwell and Casey, 1976; Nakano et al., 2003). However, a very thin dermis layer in the caudal fin of A. superciliosus, combined with its stiffness through tactility, indicates that $A$. superciliosus may not employ the 'over-the-head' tail-swing strike seen in A. pelagicus and A. vulpinus. Rather, A. superciliosus may swing its tail laterally rather than over the head.

The thorn-like scales with a low scale density at SS-B in Alopias superciliosus (Figs. 5B, 5A, B) as well as its close clustering of its plots of scale shapes with those of slow swimming lamniforms (Figs. 5, 6) strongly suggest that A. superciliosus is a slow swimming shark, at least relative to A. pelagicus and A. vulpinus. Yet, the dermis layer on the body (SS-B) in A. superciliosus is thicker than that of A. pelagicus and A. vulpinus, meaning that the body of $A$. 
superciliosus is capable of extreme bending. Its slow swimming ability would make it difficult to initiate the burst of speed necessary to use the caudal fin for hunting as seen in the other two species of Alopias. However, its inferred extreme body bending ability would allow A. superciliosus to maximize the lateral slapping motion of its stiff caudal fin to stun its prey, compensating its slow swimming. Nakano et al. (2003) found that A. superciliosus is more active at night and suggested that the upward directed larger eyes would be beneficial for hunting fish at night, coming at its prey as it slowly ascends. Along with these behavioral interpretations, its slow swimming with a powerful lateral swing of its stiff caudal fin made possible by the extreme bending of the body suggests that the primary hunting strategy of A. superciliosus may be by ambushing its prey, rather than actively hunting it.

The swimming ability and prey hunting strategies of Alopias superciliosus inferred from my integument-based analyses are consistent with what have been so far observed for the species, even though the typical feeding behavior of this species have never been directly recorded or observed (e.g., Stillwell and Casey, 1976; Nakano et al., 2003). However, what has become even more evident through my study is the need for further observations and analyses on the biology of Pseudocarcharias, commonly referred to as a 'strong active swimmer' (Compagno, 2002; Ebert et al., 2013) but has a caudal fin skeleton reminiscent of slow swimming lamniforms (e.g., Kim et al., 2013). For example, my average interkeel distance and scale density data of Pseudocarcharias show that they are overall comparable to fast swimming Lamna (Fig. 5A, B), whereas plots of Pseudocarcharias in my scale shape analyses are mostly clustered closely with plots of slow swimming Mitsukurina and Megachasma. This mosaic of conflicting results for Pseudocarcharias not only suggests that further studies are needed to elucidate the biology of Pseudocarcharias, but also some aspects of my integumentary variables 
may not necessarily accurately signal the swimming ability of sharks, warranting further investigations.

\section{Evolutionary patterns of lamniform integument}

I used previously published molecular-based and morphology-based phylogenetic trees to examine the evolutionary patterns in scale densities and average interkeel distances within the order Lamniformes through character mapping (Fig. 8). In both trees, Mitsukurina is the most basal lamniform. The average interkeel distance data of Mitsukurina are not reflective of its swimming ability (see above). However, Mitsukurina has thorn-like placoid scales (Fig. 4D) that have more protective function than swimming efficiency (see above), and the species exhibits the lowest scale densities among all the examined taxa in both trees (Fig. 8). Therefore, slow swimming is interpreted to be a plesiomorphic condition in Lamniformes.

The molecular-based tree places the Alopias clade as a sister to a clade consisting of Megachasma and Pseudocarcharias, and the two clades together form a clade that is sister to Lamna (Fig. 8A). On the other hand, in the morphology-based tree (Fig. 8B), Pseudocarcharias is the next successive least derived lamniform to Mitsukurina, followed by Megachasma that is sister to a clade consisting of Alopias spp. and Lamna. In both trees (Fig. 8A, B), Alopias spp. have exceptionally high scale densities and low average interkeel distances, and the quantitative trends are particularly prominent in scales on their caudal fin (i.e., SS-0, SS-45, and SS-90), reflecting their tail-slapping behavior which requires high speed. Although the average interkeel distance data show no specific pattern, comparisons of scale density data exclusively at SS-B reveal that the only lamniform that has comparable measurements to Alopias spp. (values ranging 52-132 among the three species) is Lamna (value of 72). The significance of my 
integumentary measurements for Pseudocarcharias is rather tenuous (see above), but the morphology-based tree overall shows an increase in scale density (= increase in swimming efficiency) through lamniform phylogeny. In contrast, in the molecular-based tree, the Alopias clade is sister to a clade containing slow swimming Megachasma, rather than to fast swimming Lamna, implying that fast swimming evolved more than once in the lamniform phylogeny. Therefore, from the standpoint of the possible evolutionary pattern of integumentary structures, the morphology-based phylogenetic tree offers a more parsimonious interpretation than the molecular-based tree.

\section{CONCLUSION}

Morphological examinations have contributed to a multitude of disciplines including genetics, phylogeny, ontogeny, ecology, and ethology (Betz, 2006). Ecomorphology is a branch of biology that attempts to compare the relationship between an organism's anatomy and the connection to its life history patterns (Motta and Kotrschal, 1991). Although a relatively understudied scientific field, ecomorphology has emerged as an excellent tool for understanding functional morphology in a broad ecological and evolutionary framework (Wainwright, 1994; Foote, 1997; Ankhelyi et al., 2018). The strength of ecomorphology lies in its ability to connect intrinsic characteristics of an organism with the environment in which they live (Norton et al., 1995). Elasmobranch species are generally difficult to investigate through field studies, including estimates of routine swimming speeds (Lauder and Di Santo, 2015). In this present study, I inferred the swimming behavior and prey hunting strategy of elusive Alopias superciliosus using an ecomorphological approach by relating integumentary structures to known observations and information about the swimming ability and hunting behaviors of sharks. 
I examined the following four integumentary variables of selected fast swimming $(A$. pelagicus, A. vulpinus, and Lamna) and slow swimming (Mitsukurina and Megachasma) lamniform sharks to determine whether A. superciliosus is a fast swimmer or a slow swimmer: 1 ) dermis thickness, 2) average interkeel distances of scales, 3) scale density, and 4) scale shape. My interkeel distance and scale density data as well as thorn-like scales on the body indicate that A. superciliosus is a slower swimmer than A. pelagicus and A. vulpinus, but can move its caudal fin as fast as, or as efficiently as, A. pelagicus and A. vulpinus. My dermis thickness data suggest that A. superciliosus has a flexible body like A. pelagicus and A. vulpinus, but its caudal fin is interpreted to be considerably 'stiff' with no extreme bending capability. PCA-based and CVAbased quantitative analyses show that the scale shapes of $A$. superciliosus are overall more similar to slow swimming Mitsukurina and Megachasma than to fast swimming A. pelagicus, A. vulpinus, and Lamna, although my Euclidian distance tree by taxa demonstrates that the scale shapes of Mitsukurina are quite different from the rest of the examined lamniforms by being thorn-like. To capture small schooling fish, A. pelagicus and A. vulpinus employ an 'over-thehead' tail-swing strike as the forward motion of the body comes to a sudden stop (Oliver et al., 2013). Like A. pelagicus and A. vulpinus, A. superciliosus is commonly tail-hooked through longline fishery (Stillwell and Casey, 1976; Nakano et al., 2003) and has high scale densities like the other two species of Alopias, suited to accommodate abrasion. These observations suggest that A. superciliosus must also use its caudal fin for prey capture. However, a very thin dermis layer in the caudal fin of $A$. superciliosus, combined with its stiffness through tactility, indicates that the species is not capable of swinging its caudal fin over the head like A. pelagicus and A. vulpinus, but rather must employ a simple laterally directed tail-slap to capture its prey. The thick dermis layer on the body in A. superciliosus indicates its extreme body bending capability, 
perhaps to maximize the strike power of the tail-slap in order to compensate its slow swimming. By taking all these pieces of information into account, A. superciliosus is interpreted to be an ambush predator, rather than an active prey-pursuing hunter.

In addition, I mapped my scale density and average interkeel distance data on to previously published molecular-based and morphology-based phylogenetic trees to examine their evolutionary patterns within the order Lamniformes. My character mapping suggests that the slow swimming is a plesiomorphic condition in Lamniformes. The morphology-based tree overall suggests an increase in swimming efficiency through lamniform phylogeny, whereas the molecular-based tree suggests that fast swimming evolved more than once in the lamniform phylogeny. Therefore, from the integumentary standpoint, the morphology-based phylogenetic tree offers a more parsimonious interpretation that the molecular-based tree in regards to the evolution of swimming efficiency in lamniforms inferred from their integumentary data.

Future studies should attempt to document the behavior of A. superciliosus to confirm its slow swimming and laterally directed tail-slapping behavior through direct observations in the wild. Recent studies also examined the ability of sharks being able to flex their scales using passive or active scale actuation, known as 'bristling' (Bechert et al., 2000), which can also reduce the surface drag on sharks in addition to the static effects of scale surface morphology (Motta et al., 2012; Lang et al., 2014; Afroz et al., 2016; Du Clos et al., 2018). Whereas these studies were primarily focused on the short fin mako shark (Isurus oxyrinchus), future studies should attempt to examine the potential of scale flexibility and surface drag reduction not only within the family Alopiidae, but a more comprehensive comparison within the order Lamniformes, as well. Doing so may help identify the elusive swimming behavior of $A$. superciliosus by further clarifying other morphological features of its scales. Another major 
morphological attribute of the caudal fin in sharks is the vertebral column, specifically number of vertebra, which has been studied extensively regarding its role in locomotion as well as bending of the body under stress (Lauder, 1989; Wu, 1997; Brainerd and Patek, 1998; Nowroozi and Brainerd, 2014). Future studies could focus on quantifying the number of vertebra within the order Lamniformes for another broad examination of how form contributes to function. Another noteworthy issue that stems from an unexpected outcome of my study is the realization that the swimming efficiency of Pseudocarcharias is even more perplexing. For instance, my average interkeel distance and scale density data of Pseudocarcharias indicate that it is a fast swimming shark, but my scale shape analyses show the species to be a slow swimmer. These results in turn suggest that there may be some species-specific limitations in my integumentary variables that may not adequately help decipher the swimming ability of sharks.

Lamniformes is a small but behaviorally and ecologically diverse order of sharks that serve as an excellent example of the diversity of form and function. Although only about half of the species within the order Lamniformes were examined (cf. Fig. 1), my present study represents the most extensive comparative investigation of the morphology and variation of integumentary structures, especially placoid scales, conducted for this shark order. The examinations of the biology of these sharks, including my study, will not only help craft a better understanding of the evolution of sharks and their morphology in general, but also how to better conserve their unique ecological attributes. 


\section{LITERATURE CITED}

Aalbers, S. A., D. Bernal, and C. A. Sepulveda. 2010. The functional role of the caudal fin in the feeding ecology of the common thresher shark Alopias vulpinus. Journal of Fish Biology $76: 1863-1868$.

Adams, D. C., F. J. Rohlf, and D. E. Slice. 2013. A field comes of age: geometric morphometrics in the 21st century. Hystrix 24:7-14.

Afroz, F., A. Lang, M. L. Habegger, P. Motta, and R. Hueter. 2016. Experimental study of laminar and turbulent boundary layer separation control of shark skin. Bioinspiration \& Biomimetics 12:016009.

Ankhelyi, M. V., D. K. Wainwright, and G. V. Lauder. 2018. Diversity of dermal denticle structure in sharks: skin surface roughness and three-dimensional morphology. Journal of Morphology 279:1-23.

Bechert, D. W., G. Hoppe, and W.-E. Reif. 1985. On the drag reduction of the shark skin. American Institute of Aeronautics and Astronautics Paper Number 85-0546:1-18.

Bechert, D. W., M. Bruse, W. Hage, and R. Meyer. 2000. Fluid mechanics of biological surfaces and their technological application. Naturwissenschaften 87:157-171.

Betz, O. 2006. Ecomorphology: integration of form, function, and ecology in the analysis of morphological structures. Mitteilungen der Deutschen Entomologiachen Gesellschaft $15: 409-416$.

Brainerd, E. L., and S. N. Patek. 1998. Vertebral column morphology, C-start curvature, and the evolution of mechanical defenses in tetraodontiform fishes. Copeia 1998:971-984. 
Castro, J. I. 2010. The Sharks of North America. Oxford University Press, New York, New York.

Cartamil, D., N. C. Wegner, S. Aalbers, C. A. Sepulveda, C. A. Baquero, and J. B. Graham. 2010. Diel movement patterns and habitat preferences of the common thresher shark (Alopias vulpinus) in the Southern California Bight. Marine and Freshwater Research 61:596-604.

Compagno, L. J. V. 1990. Relationships of the megamouth shark, Megachasma pelagios (Lamniformes: Megachasmidae), with comments on its feeding habits. National Oceanic and Atmospheric Administration Technical Report, National Marine Fisheries Service 90:357-379.

Compagno, L. J. V. 2002. Sharks of the world: an annotated and illustrated catalogue of shark species known to date. Volume 2. Bullhead, mackerel and carpet sharks (Heterodontiformes, Lamniformes and Orectolobiformes). Food and Agriculture Organization Species Catalogue for Fishery Purposes 1(2):1-269.

Cooper, R. L., A. P. Thiery, A. G. Fletcher, D. J. Delbarre, L. J. Rasch, and G. J. Fraser. 2018. An ancient turing-like patterning mechanism regulates skin denticle development in sharks. Science Advances 4(11):1-10.

Du Clos, K. T., A. Lang, S. Devey, P. J. Motta, M. L. Habegger, and B. J. Gemmell. 2018. Passive bristling of mako shark scales in reversing flows. Journal of the Royal Society Interface 15:20180473.

Ebert, D. A., S. Fowler, L. Compagno, and M. Dando. 2013. Sharks of the World: A Fully Illustrated Guide. Wild Nature Press, Plymouth, New Hampshire. 
Foote, M. 1997. The evolution of morphological diversity. Annual Review of Ecology and Systematics 28:129-152.

Fourie, J. 1982. Gold in electron microscopy. Gold Bulletin 15:2-6.

Gemballa, S., P. Konstantinidis, J. M. Donley, C. Sepulveda, and R. E. Shadwick. 2006. Evolution of high-performance swimming in sharks: transformations of the musculotendinous system from subcarangiform to thunniform swimmers. Journal of Morphology 267:477-493.

Gruber, S. H., and L. J. V. Compagno. 1981. Taxonomic status and biology of the bigeye thresher, Alopias superciliosus. Fishery Bulletin 79:617-640.

Gunz, P., and P. Mitteroecker. 2013. Semilandmarks: a method for quantifying curves and surfaces. Hystrix 24:103-109.

Hammer, Ø., D. A. T. Harper, and P. D. Ryan. 2001. PAST: Paleontological statistics software package for education and data analysis. Palaeontologia Electronica 4:1-9.

Harvey, P. H., and M. D. Pagel. 1991. The Comparative Method in Evolutionary Biology. Oxford University Press, New York, New York.

Heinicke, M. P., G. J. P. Naylor, and S. B. Hedges. 2009. Cartilaginous fishes (Chondrichthyes); pp. 320-327 in S. B. Hedges, and S. Kumar (eds.), The Timetree of Life. Oxford University Press, Oxford.

Helfman, G. S., B. B. Collette, D. E. Facey, and B. W. Bowen. 2009. The Diversity of Fishes: Biology, Evolution, and Ecology. Wiley-Blackwell, Hoboken, New Jersey.

Holts, D. B., and D. W. Bedford. 1993. Horizontal and vertical movement of the shortfin mako shark, Isurus oxyrinchus, in the southern California bight. Australian Journal of Marine and Freshwater Research 44:901-909. 
Human, B. A., E. P. Owen, L. J. V. Compagno, and E. H. Harley. 2006. Testing morphologically based phylogenetic theories within the cartilaginous fishes with molecular data, with special reference to the catshark family (Chondrichthyes; Scyliorhinidae) and the interrelationships within them. Molecular Phylogenetics and Evolution 39:384-391.

Jiang, S., X. Cheng, Y. Ma, and X. Wang. 2016. A new archaeopterodactyloid pterosaur from the Jiufotang Formation of western Liaoning, China, with a comparison of sterna in Pterodactylomorpha. Journal of Vertebrate Paleontology 36:2-14.

Kim, S. H., K. Shimada, and C. K. Rigsby. 2013. Anatomy and evolution of heterocercal tail in lamniform sharks. Anatomical Record 296:433-442.

Klimley, A. P. 2013. The Biology of Sharks and Rays. University of Chicago Press, Chicago, Illinois.

Klingenberg, C. P. 2011. MorphoJ: an integrated software package for geometric morphometrics. Molecular Ecology Resources 11:353-357.

Lang, A., M. T. Bradshaw, J. A. Smith, J. N. Wheelus, P. Motta, M. L. Habegger, and R. E. Hueter. 2014. Movable shark scales act as a passive dynamic micro-roughness to control flow separation. Bioinspiration \& Biomimetics 9:036017.

Lauder, G. V. 1989. Caudal fin locomotion in ray-finned fishes: historical and functional analyses. American Zoologist 29:85-102.

Lauder, G. V., and V. Di Santo. 2015. Swimming mechanics and energetics of elasmobranch fishes. Fish Physiology 34:219-253.

Legendre, P., and L. F. Legendre. 2012. Numerical Ecology. Elsevier, Amsterdam, Netherlands. Lingham-Soliar, T. 2005. Caudal fin in the white shark, Carcharodon carcharias (Lamnidae): a dynamic propeller for fast, efficient swimming. Journal of Morphology 264:233-252. 
Lowe, C. G. 2002. Bioenergetics of free-ranging juvenile scalloped hammerhead sharks (Sphyrna lewini) in Kane'ohe Bay, O'ahu, HI. Journal of Experimental Marine Biology and Ecology 278:141-156.

Luna, L. G. 1968. Manual of histologic staining methods of the Armed Forces Institute of Pathology. Pathology 3(3):249.

Martin, A. P., A. T. Pardini, L. R. Noble, and C. S. Jones. 2002. Conservation of a dinucleotide simple sequence repeat locus in sharks. Molecular Phylogenetics and Evolution 23:205213.

Meyer, W., and U. Seegers. 2012. Basics of skin structure and function in elasmobranchs: a review. Journal of Fish Biology 80:1940-1967.

Motta, P. J. 1977. Anatomy and functional morphology of dermal collagen fibers in sharks. Copeia 1977:454-464.

Motta, P., M. L. Habegger, A. Lang, R. Hueter, and J. Davis. 2012. Scale morphology and flexibility in the shortfin mako Isurus oxyrinchus and the blacktip shark Carcharhinus limbatus. Journal of Morphology 273:1096-1110.

Motta, P. J., and K. M. Kotrschal. 1991. Correlative, experimental, and comparative evolutionary approaches in ecomorphology. Netherlands Journal of Zoology 42:400-415.

Moyle, P. B., and J. J. Cech. 1996. Fishes: An Introduction to Ichthyology. Prentice Hall, Englewood Cliffs, New Jersey.

Nakano, H., H. Matsunaga, H. Okamoto, and M. Okazaki. 2003. Acoustic tracking of bigeye thresher shark Alopias superciliosus in the eastern Pacific Ocean. Marine Ecology Progress Series 265:255-261. 
Nakaya, K., T. Tomita, K. Suda, K. Sato, K. Ogimoto, A. Chappell, T. Sato, K. Takano, and Y. Yuki. 2016. Slingshot feeding of the goblin shark Mitsukurina owstoni (Pices: Lamniformes: Mitsukurinidae). Scientific Reports 6:27786.

Naylor, G. J. P., J. N. Caira, K. Jensen, K. A. M. Rosana, N. Straube, and C. Lakner. 2012. Elasmobranch phylogeny: a mitochondrial estimate based on 595 species; pp. 31-57 in J. C. Carrier, J. A. Musick, and M. R. Heithaus (eds.), The Biology of Sharks and Their Relatives. CRC Press, Boca Raton, Florida.

Naylor, G. J. P., A. P. Martin, E. G. Mattison, and W. M. Brown. 1997. Interrelationships of lamniform sharks: testing phylogenetic hypothesis with sequence data; pp. 199-218 in T. D. Kocher, and C. A. Stepien (eds.), Molecular Systematics of Fishes. Academic Press, San Diego, California.

Nelson, D. R., J. N. McKibben, W. R. Strong, Jr., C. G. Lowe, J. A. Sisneros, D. M. Schroeder, R. J. Lavenberg. 1997. An acoustic tracking of a megamouth shark, Megachasma pelagios: a crepuscular vertical migrator. Environmental Biology of Fishes 49:389-399.

Norton, S. F., J. J. Luczkovich, and P. J. Motta. 1995. The role of ecomorphological studies in the comparative biology of fishes; pp. 287-304 in J. J. Luczkovich, P. J. Motta, S. F. Norton, and K. F. Liem (eds.), Ecomorphology of Fishes. Springer, Dordrecht, Netherlands.

Nowroozi, B. N. and E. L. Brainerd. 2014. Importance of mechanics and kinematics in determining the stiffness contribution of the vertebral column during body-caudal-fin swimming in fishes. Zoology 117(1):28-35.

Oliver, S. P., J. R. Turner, K. Gann, M. Silvosa, and T. D. U. Jackson. 2013. Thresher sharks use tail-slaps as a hunting strategy. PloS One 8(7):e67380. 
Preti, A., S. E. Smith, and D. Ramon. 2001. Feeding habits of the common thresher shark (Alopias vulpinus) sampled from the California-based drift gill net fishery, 1998-1999. California Cooperative Oceanic Fisheries Investigations Report 49:145-152.

Preti, A., S. E. Smith, and D. A. Ramon. 2004. Diet differences in the thresher shark (Alopias vulpinus) during transition from a warm-water regime to a cool-water regime off California-Oregon, 1998-2000. California Cooperative Oceanic Fisheries Investigations Report 45:118-125.

Raschi, W. G., and J. A. Musick. 1986. Hydrodynamic aspects of shark scales. NASA Contractor Report 3963:1-124.

Raschi, W. G., and C. Tabit. 1992. Functional aspects of placoid scales: a review and update. Marine and Freshwater Research 43:123-147.

Reif, W.-E. 1982. Morphogenesis and function of the squamation in sharks. Neues Jahrbuch für Geologie und Paläontologie, Abhandlungen 164:172-183.

Reif, W. -E. 1985. Morphology and hydrodynamic effects of the scales of fast swimming sharks. Fortschritte der Zoologie 30:483-485.

Reif, W.-E., and A. Dinkelacker. 1982. Hydrodynamics of the squamation in fast swimming sharks. Neues Jahrbuch für Geologie und Paläontologie, Abhandlungen 164:184-187.

Rohlf, F. J. 1998. On applications of geometric morphometrics to studies of ontogeny and phylogeny. Systematic Biology 47:147-158.

Saunders, R., F. Royer, and M. Clarke. 2011. Winter migration and diving behaviour of porbeagle shark, Lamna nasus, in the Northeast Atlantic. ICES Journal of Marine Science 68:166-174. 
Schneider, C. A., W. S. Rasband, and K. W. Eliceiri. 2012. NIH Image to ImageJ: 25 years of image analysis. Nature Methods 9:671-675.

Shimada, K. 2005. Phylogeny of lamniform sharks (Chondrichthyes: Elasmobranchii) and the contribution of dental characters to lamniform systematics. Paleontological Research 9:55-72.

Shirai, S. 1996. Phylogenetic interrelationships of neoselachians (Chondrichthyes: Euselachii); pp. 9-34 in M. L. J. Stiassny, L. R. Parenti, and G. D. Johnson (eds.), Interrelationships of Fishes. Academic Press, San Diego, California.

Sokal, R. R. 1958. A statistical method for evaluating systematic relationships. University Kansas Science Bulletin 38:1409-1438.

Southall, E. J., and D. W. Sims. 2003. Shark skin: a function in feeding. Proceedings of the Royal Society of London B: Biological Sciences 270:S47-S49.

Stillwell, C. E., and J. G. Casey. 1976. Observations on the bigeye thresher shark, Alopias superciliosus, in the Western North Atlantic. Fishery Bulletin 74:221-225.

Strong, W. R., R. C. Murphey, B. D. Bruce, D. R. Nelson. 1992. Movements and associated observations of bait-attracted white sharks, Carcharodon carcharias: a preliminary report. Australian Journal of Freshwater and Marine Research 43:13-20.

Thomson, K. S. 1976. On the heterocercal tail in sharks. Paleobiology 2:19-38.

Thomson, K. S., and D. E. Simanek. 1977. Body form and locomotion in sharks. American Zoologist 17:343-354.

Tomita, T., S. Tanaka, K. Sato, and K. Nakaya. 2014. Pectoral fin of the megamouth shark: skeletal and muscular systems, skin histology, and functional morphology. PloS One 9:e86205. 
Vélez-Zuazo, X., and I. Agnarsson. 2011. Shark tales: a molecular species-level phylogeny of sharks (Selachimorpha, Chondrichthyes). Molecular Phylogenetics and Evolution 58:207-217.

Watanabe, Y. Y., K. J. Goldman, J. E. Caselle, D. D. Chapman, and Y. P. Papastamatiou. 2015. Comparative analyses of animal-tracking data reveal ecological significance of endothermy in fishes. Proceedings of the National Academy of Sciences 112(19):1500316112.

Wainwright, P. C. 1994. Functional morphology as a tool in ecological research; pp. 42-59 in P. C. Wainwright, and S. M. Reilly (eds.) Ecological Morphology: Integrative Organismal Biology. University of Chicago Press, Chicago, Illinois.

Webb, P. W. 1984. Body form, locomotion and foraging in aquatic vertebrates. American Zoologist 24:107-120.

Welton, B. J., and R. F. Farish. 1993. The Collector's Guide to Fossil Sharks and Rays from the Cretaceous of Texas. Before Time, Lewisville, Texas.

Weng, K. C., D. C. Foley, J. E. Ganong, C. Perle, G. L. Shillinger, B. A. Block. 2008. Migration of an upper trophic level predator, the salmon shark Lamna ditropis, between distant ecoregions. Marine Ecology Progress Series 372:253-264.

Wilga, C. D., and G. V. Lauder. 2004. Biomechanics: hydrodynamic function of the shark's tail. Nature 430:850-850.

Wu, T. Y. 1977. Introduction to the scaling of aquatic animal locomotion. Defense Technical Information Center, Fort Belvoir, Virginia.

Zelditch, M. L., D. L. Swiderski, and H. D. Sheets. 2012. Geometric Morphometrics for Biologists: A Primer. Academic Press, New York, New York. 
Table 1. Characterization of swimming speed ('fast' vs. 'slow') in this study for each lamniform species examined and its source (see text for further explanation)

\begin{tabular}{|c|c|c|}
\hline Species & Speed & Source(s) \\
\hline Alopias pelagicus & Fast & $16 \mathrm{~km} \cdot \mathrm{h}^{-1}-50 \mathrm{~km} \cdot \mathrm{h}^{-1} *($ Oliver et al., 2 \\
\hline Alopias superciliosus & Uncertain & $\begin{array}{l}1.3-2.0 \mathrm{~km} \cdot \mathrm{h}^{-1} \text { (Nakano et al., 2003) } \\
\text { 'Fast' (Kim et al., 2013) }\end{array}$ \\
\hline Alopias vulpinus & Fast & $2.1 \mathrm{~km} \cdot \mathrm{h}^{-1}$ (Cartamil et al., 2010) \\
\hline Mitsukurina owstoni & Slow & 'Slow' (Nakaya et al., 2016) \\
\hline Pseudocarcharias kamoharai & Uncertain & $\begin{array}{l}\text { 'Strong active swimmer'? (Ebert et al., 2013) } \\
\text { 'Slow' (Kim et al., 2013) }\end{array}$ \\
\hline Megachasma pelagios & Slow & $1.5 \mathrm{~km} \cdot \mathrm{h}^{-1}$ (Nelson et al., 1997) \\
\hline Lamna ditropis & Fast & $\begin{array}{l}\text { Up to at least(?) } 2.6 \mathrm{~km} \cdot \mathrm{h}^{-1} \text { (Weng et al., 2008)** } \\
3.9 \mathrm{~km} \cdot \mathrm{h}^{-1} \text { (Watanabe et al., 2015) }\end{array}$ \\
\hline \multicolumn{3}{|c|}{$\begin{array}{l}\text { * Range of speeds based on extrapolation of early stage of caudal fin movement during prey } \\
\text { hunting (see text). } \\
\text { ** Weng et al. }(2008) \text { reported the minimum and maximum speeds recorded for } L \text {. ditropis as } \\
11-62 \mathrm{~km} \cdot \mathrm{d}^{-1}\left(=\mathrm{ca} .0 .5-2.6 \mathrm{~km} \cdot \mathrm{h}^{-1}\right) \text { with a median of } 33 \mathrm{~km} \cdot \mathrm{d}^{-1}\left(=\mathrm{ca} .1 .4 \mathrm{~km} \cdot \mathrm{h}^{-1}\right) \text { based on } \\
68 \text { individuals tracked by satellite telemetry for } 6-1,335 \text { days; however, their study was based } \\
\text { on the movement of each shark over a straight-line map distance, thus implying that these } \\
\text { reported values in general likely represent underrepresented speeds from their actual routine } \\
\text { swimming speeds, especially considering Watanabe et al.'s }(2015) \text { speed estimate of } 3.9 \\
\mathrm{~km} \cdot \mathrm{h}^{-1} \text { for the species. }\end{array}$} \\
\hline
\end{tabular}


Table 2. Mahalanobis distances between sampling site groups with distances scaled to $100 \%$ and their respective $\mathrm{p}$-values from permutations tests (1,000 permutation rounds)

\begin{tabular}{|l|l|l|l|}
\hline $\begin{array}{l}\text { Sampling } \\
\text { Site }\end{array}$ & SS-0 & SS-45 & SS-90 \\
\hline SS-45 & $55 \%$ & & \\
& $p<0.0001$ & & \\
\hline SS-90 & $83 \%$ & $84 \%$ & \\
& $p<0.0001$ & $p<0.0001$ & \\
\hline SS-B & $60 \%$ & $54 \%$ & $100 \%$ \\
& $p<0.0001$ & $p<0.0001$ & $p<0.0001$ \\
\hline
\end{tabular}


Table 3. Mahalanobis distances between scale species groups with distances scaled to $100 \%$ and their respective $\mathrm{p}$-values from permutations tests (1,000 permutation rounds)

\begin{tabular}{|c|c|c|c|c|c|c|}
\hline Species & $\begin{array}{l}\text { Alopias } \\
\text { pelagicus }\end{array}$ & $\begin{array}{l}\text { A. super- } \\
\text { ciliosus }\end{array}$ & $\begin{array}{l}\text { A. } \\
\text { vulpinus }\end{array}$ & Lamna & Mitsukurina & Megachasma \\
\hline A. superciliosus & $\begin{array}{l}79 \% \\
p<0.01\end{array}$ & & & & & \\
\hline A. vulpinus & $\begin{array}{l}25 \% \\
p<0.0005\end{array}$ & $\begin{array}{l}86 \% \\
p<0.0001\end{array}$ & & & & \\
\hline Lamna & $\begin{array}{l}43 \% \\
p<0.0034\end{array}$ & $\begin{array}{l}82 \% \\
p<0.03\end{array}$ & $\begin{array}{l}40 \% \\
p<0.0001\end{array}$ & & & \\
\hline Mitsukurina & $\begin{array}{l}100 \% \\
p<0.02\end{array}$ & $\begin{array}{l}95 \% \\
p<0.005\end{array}$ & $\begin{array}{l}93 \% \\
p<0.0002\end{array}$ & $\begin{array}{l}93 \% \\
\mathrm{p}<0.201\end{array}$ & & \\
\hline Megachasma & $\begin{array}{l}75 \% \\
p<0.002\end{array}$ & $\begin{array}{l}46 \% \\
p<0.003\end{array}$ & $\begin{array}{l}75 \% \\
p<0.0003\end{array}$ & $\begin{array}{l}67 \% \\
p<0.005\end{array}$ & $\begin{array}{l}79 \% \\
p<0.01\end{array}$ & \\
\hline Pseudocarcharias & $\begin{array}{l}69 \% \\
p<0.01\end{array}$ & $\begin{array}{l}62 \% \\
p<0.008\end{array}$ & $\begin{array}{l}65 \% \\
p<0.0001\end{array}$ & $\begin{array}{l}66 \% \\
p<0.03\end{array}$ & $\begin{array}{l}49 \% \\
p<0.02\end{array}$ & $\begin{array}{l}42 \% \\
p<0.01\end{array}$ \\
\hline
\end{tabular}




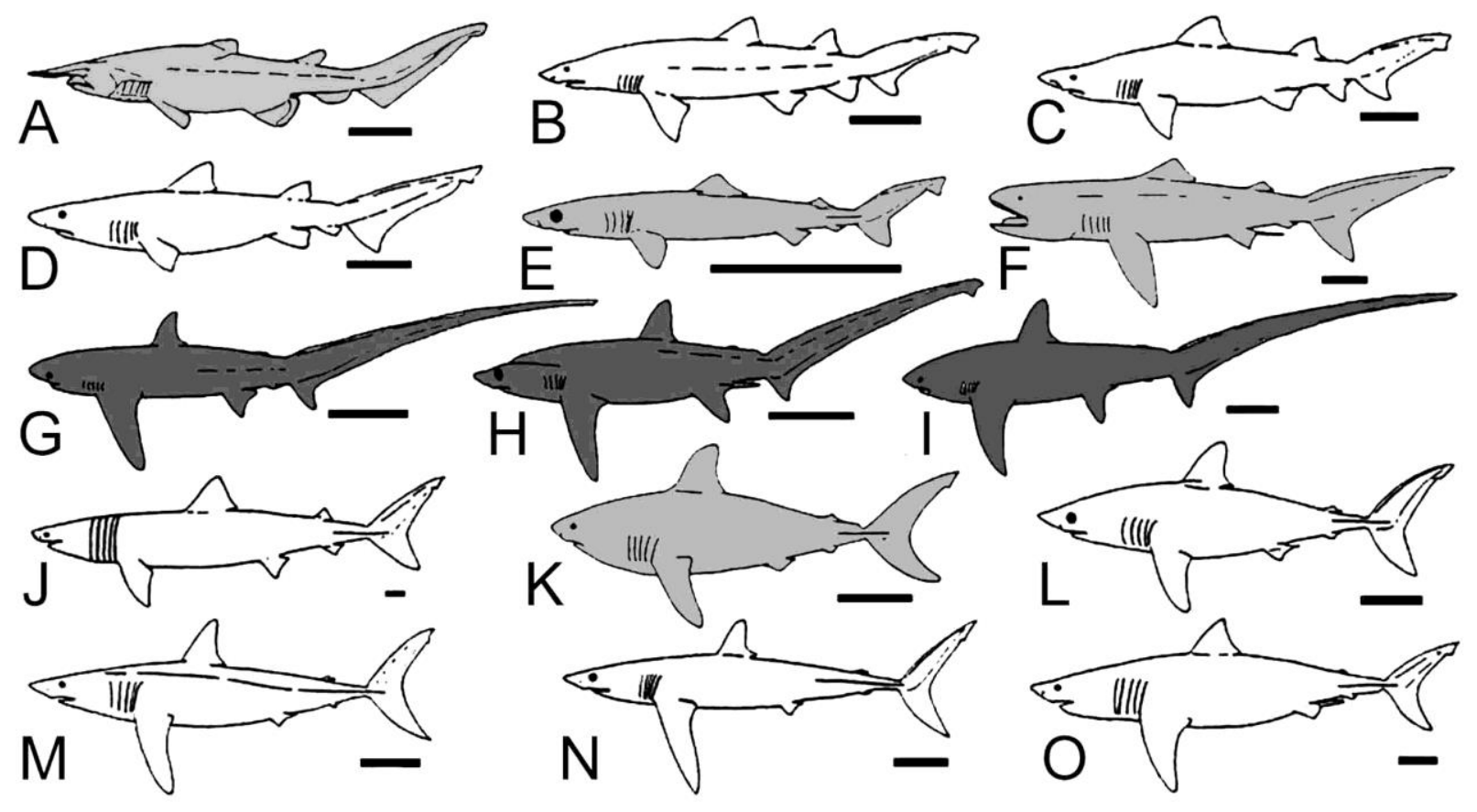

Figure 1. Fifteen species of extant lamniform sharks highlighting thresher sharks (genus Alopias; in dark gray) and four comparative species (in light gray) examined in this study (after Shimada, 2005; bar scale = $50 \mathrm{~cm}$ ). A, Mitsukurina owstoni (goblin shark); B, Carcharias taurus (sandtiger shark); C, Odontaspis ferox (smalltooth sandtiger shark); D, O. noronhai (bigeye sandtiger shark); E, Pseudocarcharias kamoharai (crocodile shark); F, Megachasma pelagios (megamouth shark); G, Alopias pelagicus (pelagic thresher shark); H, A. superciliosus (big eye thresher shark); I, A. vulpinus (common thresher shark); J, Cetorhinus maximus (basking shark); K, Lamna ditropis (salmon shark); L, L. nasus (porbeagle shark); M, Isurus oxyrinchus (shortfin mako shark); N, I. paucus (longfin mako shark); O, Carcharodon carcharias (white shark). 

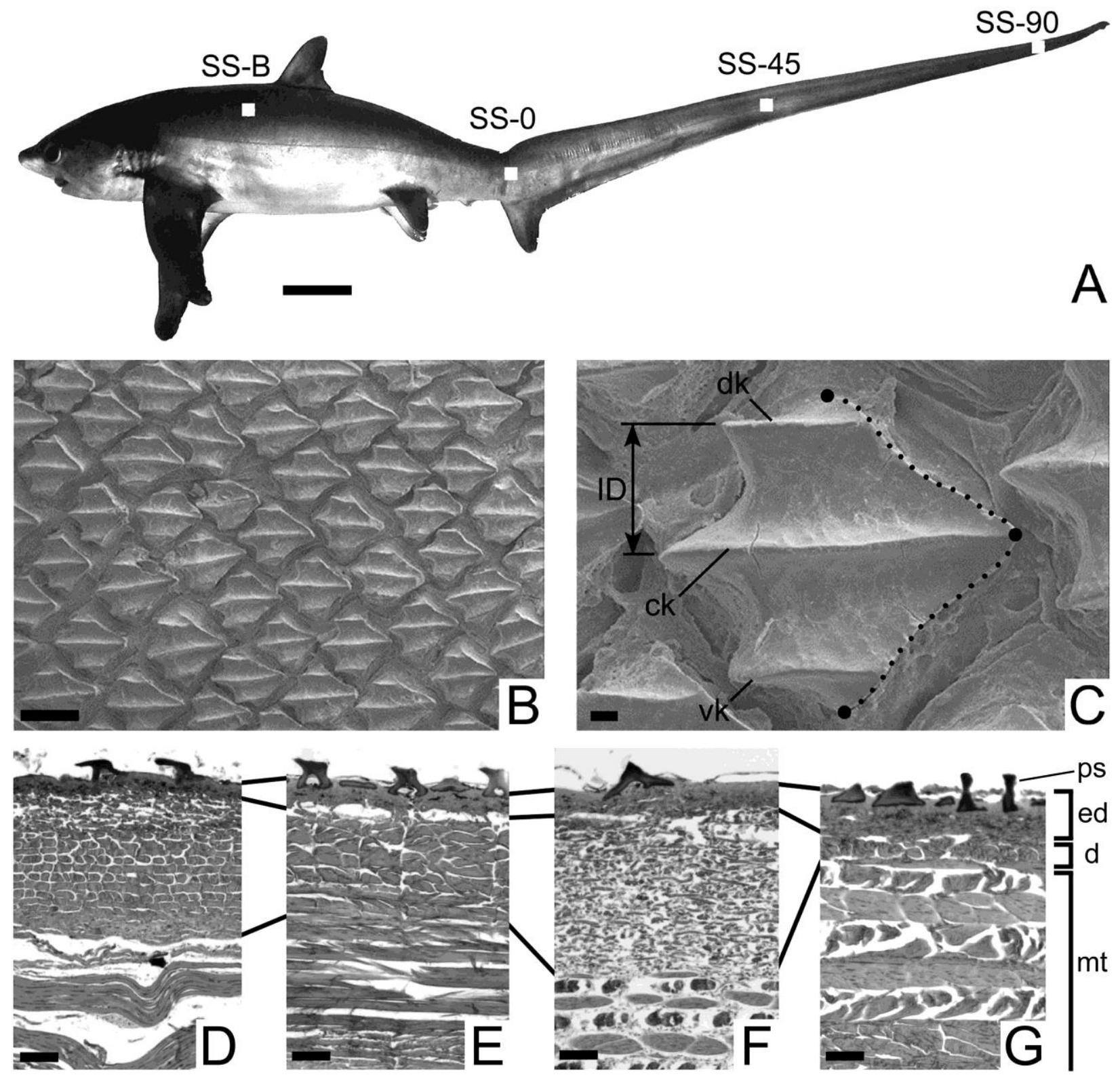

Figure 2. Integument sampling sites and example images showing examined integumentary variables in this study. A, four integument sampling sites using Alopias pelagicus (FMNH 117473; bar scale $=10 \mathrm{~cm}) ; \mathbf{B}$, scanning electron micrograph of placoid scales of Pseudocarcharias kamoharai (FMNH 117474) from SS-B at 300x magnification (anterior to left; bar scale $=200 \mu \mathrm{m}$ ); $\mathbf{C}$, scanning electron micrograph of placoid scale of $P$. kamoharai (FMNH 117474) from SS-B at 60x magnifications (anterior to left; bar scale $=20 \mu \mathrm{m}$; cf. Fig. 2B) showing the dorsal (dk), central (ck), and ventral (vk) keels as well as interkeel distance (ID) and geometric morphometric landmarks (large circles $=$ homologous landmarks; small circles $=$ semi-landmarks) for quantitative analyses; D-G, histological photographs of vertical section of integument at SS-B (D) and SS-45 (E) in A. pelagicus (FMNH 117473; cf. Fig. 2A) and at SS-B (F) and SS-45 (G) in A. superciliosus (UF 178509), showing placoid scales (ps) as well as epidermis (ed), dermis (d), and muscle tissue $(\mathrm{mt})$ layers (bar scale $=100 \mu \mathrm{m})$. 

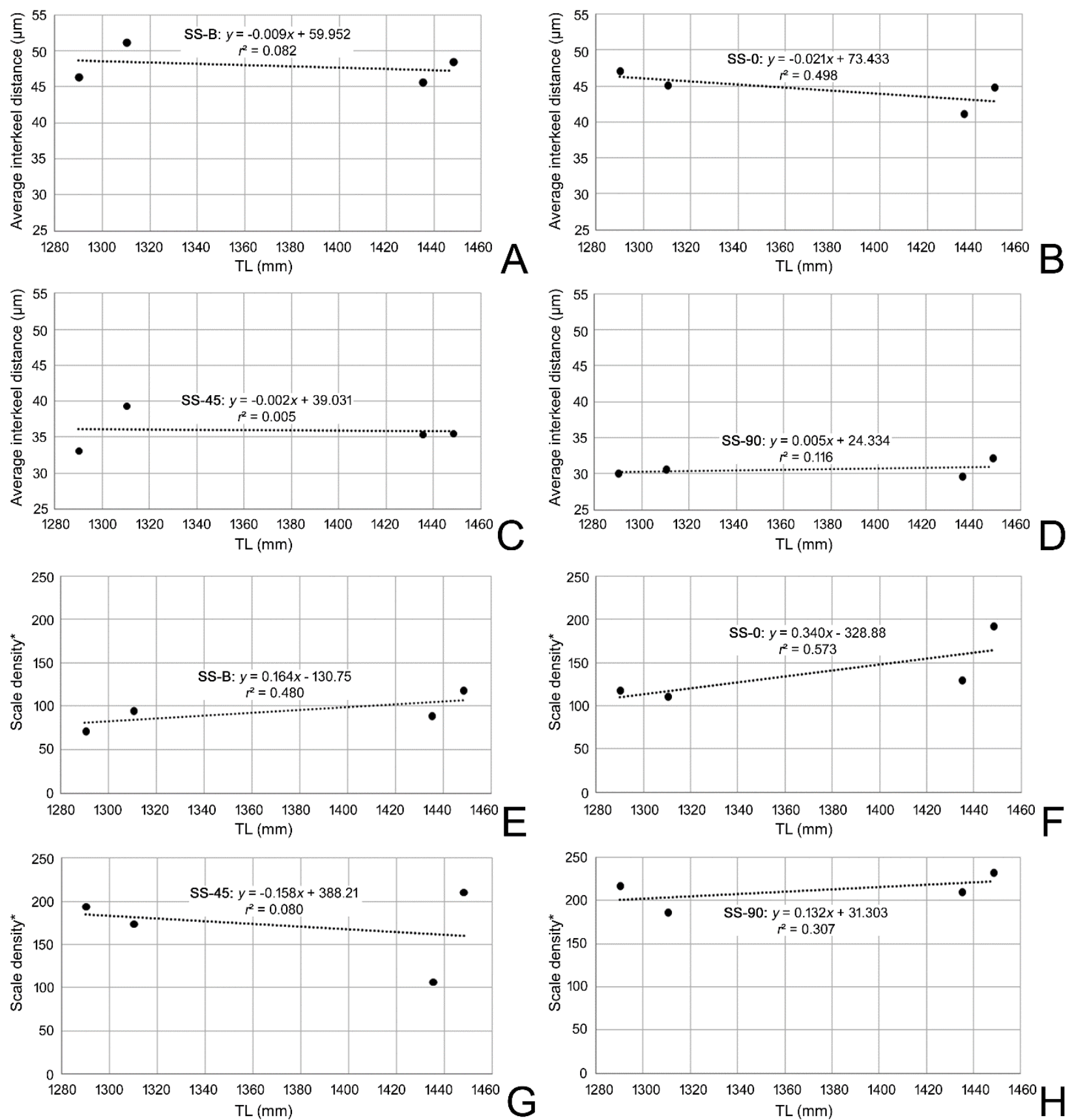

Figure 3. Regression analyses of total length by interkeel distances (A-D) and scale density (E$\mathrm{H} ;{ }^{*}=$ in $2 \mathrm{~mm} \times 1.5 \mathrm{~mm}$ viewing area) at all sampling sites (Body, SS-0, SS-45, SS-90) among the four examined specimens of Alopias vulpinus. 

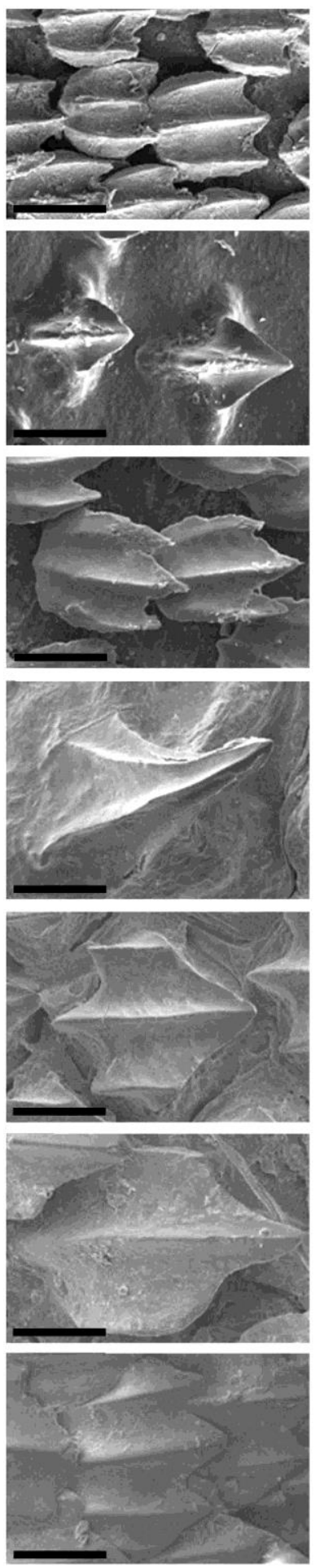
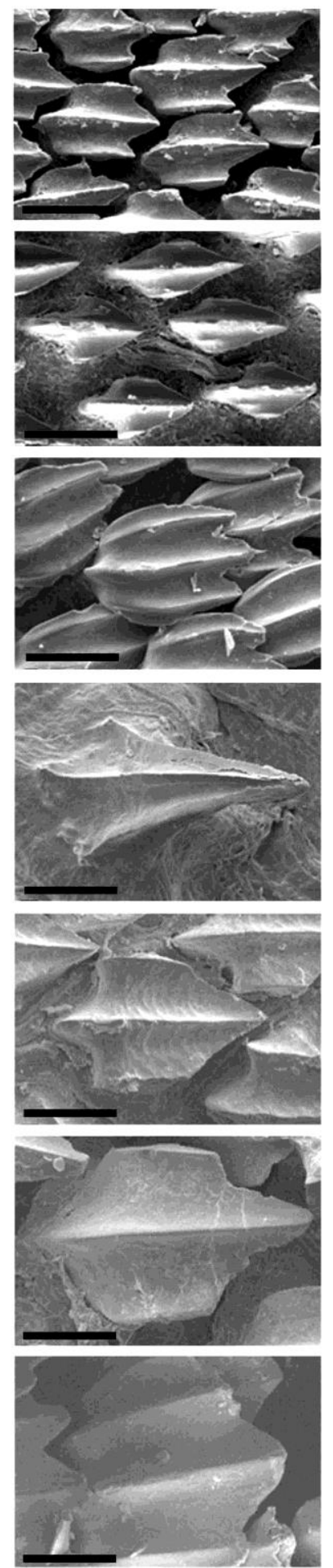
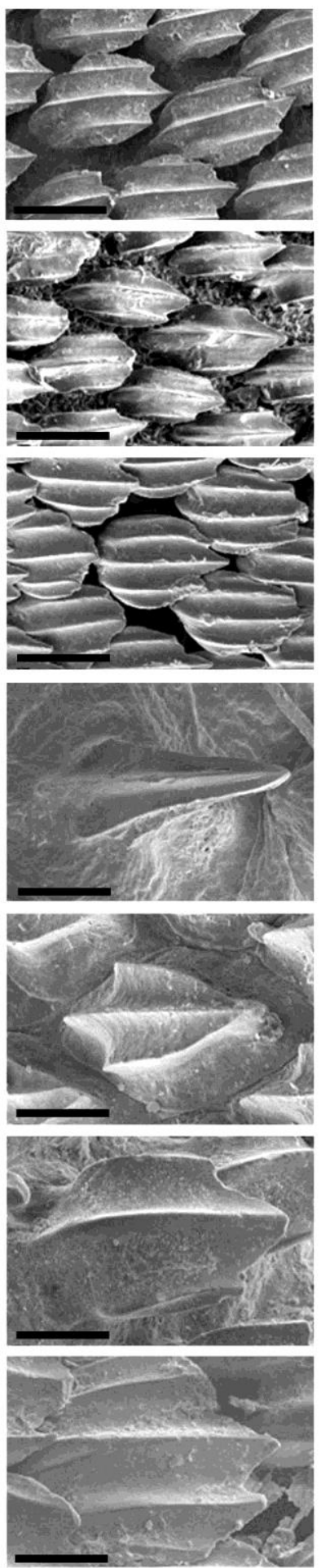
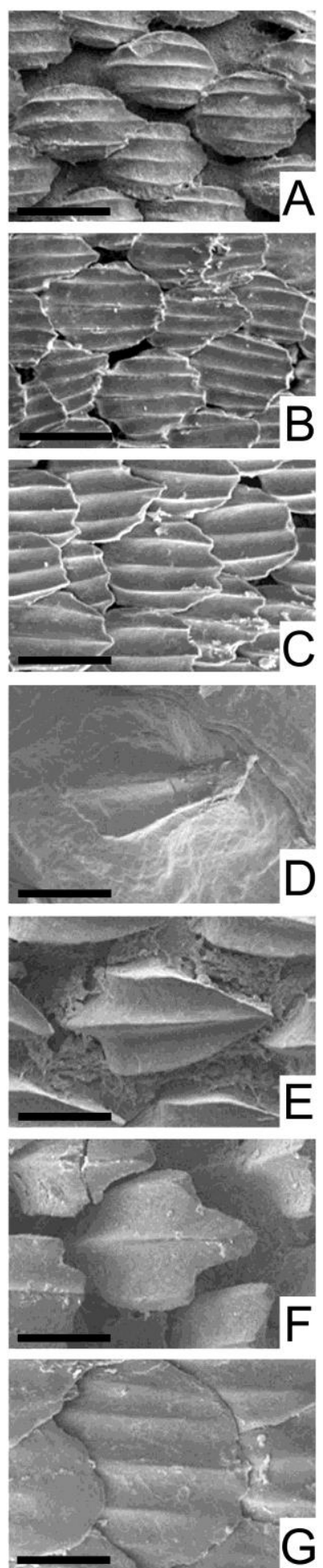

Figure 4. Scanning electron micrographs comparing morphology of placoid scales at (from left to right) SS-B, SS-0, SS-45, SS-90 (see Fig. 2A) in seven lamniform species examined (bar scale $=100 \mu \mathrm{m})$. A, Alopias pelagicus $; \mathbf{B}$, A. superciliosus $; \mathbf{C}$, A. vulpinus $; \mathbf{D}$, Mitsukurina owstoni $; \mathbf{E}$, Pseudocarcharias kamoharai; F, Megachasma pelagios; G, Lamna ditropis. 

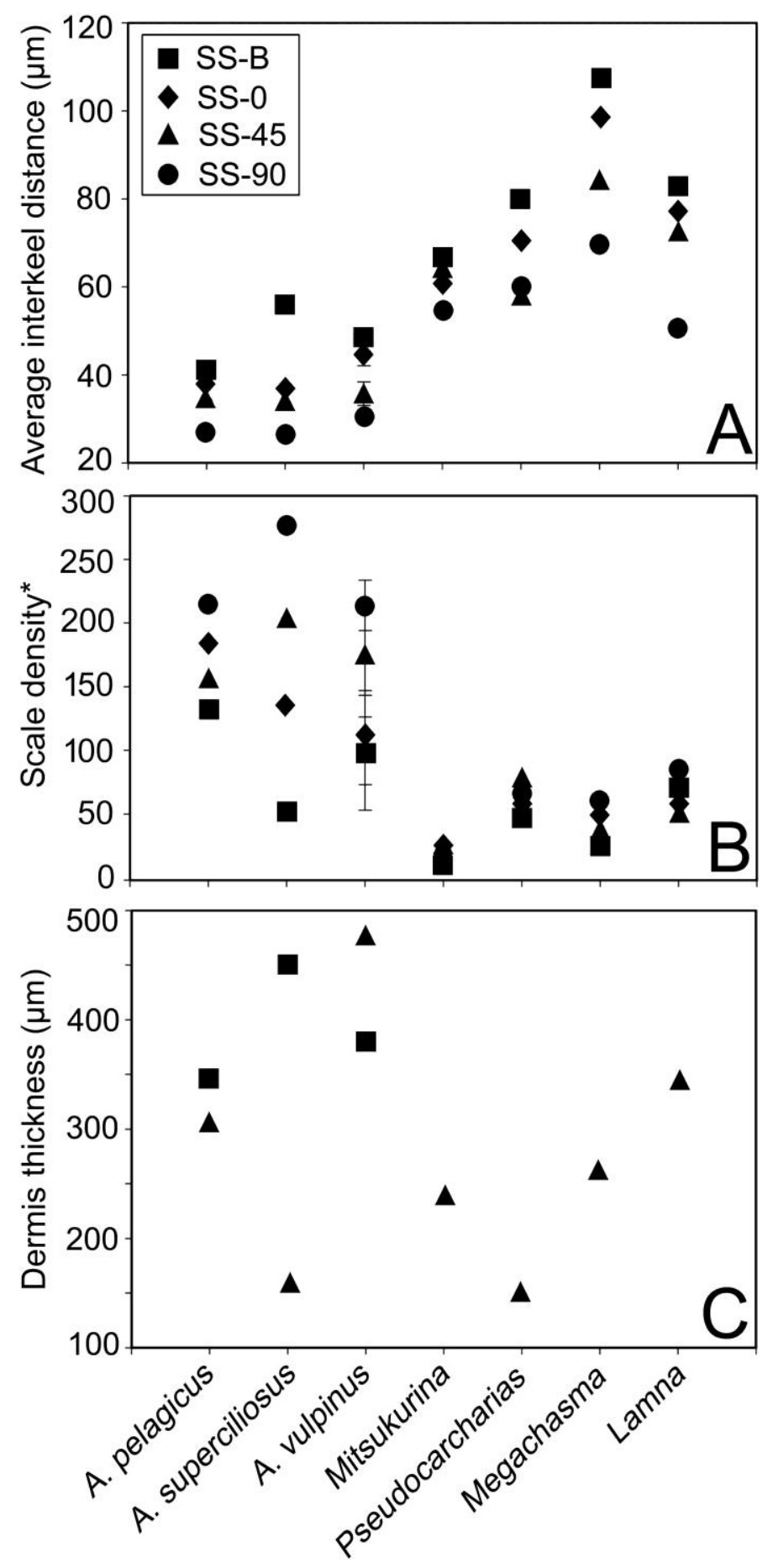

Figure 5. Graphs showing average interkeel distances (A; see Fig. 2C) and scale density (B; * = in $2 \mathrm{~mm} \times 1.5 \mathrm{~mm}$ viewing area) at four integument sampling sites (SS; see Fig. 2A; $n=4$ for Alopias vulpinus with standard deviation bars) as well as dermis thickness at SS-B and SS-45 (C) in seven lamniforms examined (no SS-B data for non-Alopias taxa; unless otherwise indicated, $n=1$ for each species: see Appendices 1, 2, 3). 

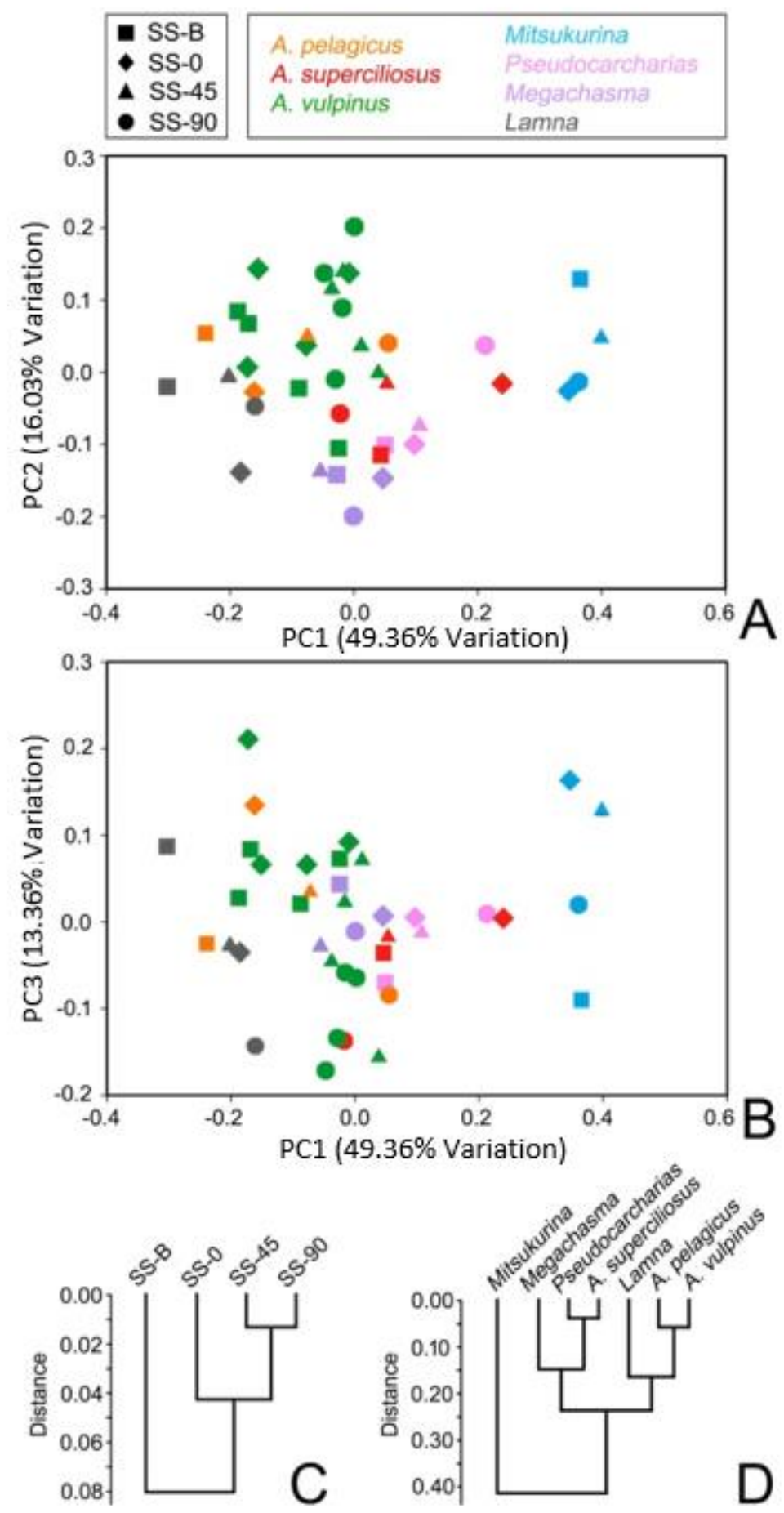

Figure 6. Graphs showing principle component (PC) analysis of placoid scales at four integument sampling sites using geometric morphometrics (A, PC1 vs. PC2; B, PC1 vs. PC3: see Appendix 4) as well as Euclidian distance trees of placoid scale morphology by sampling site (C) and by taxa (D) using Unweighted Pair Group Method with Arithmetic Means. 

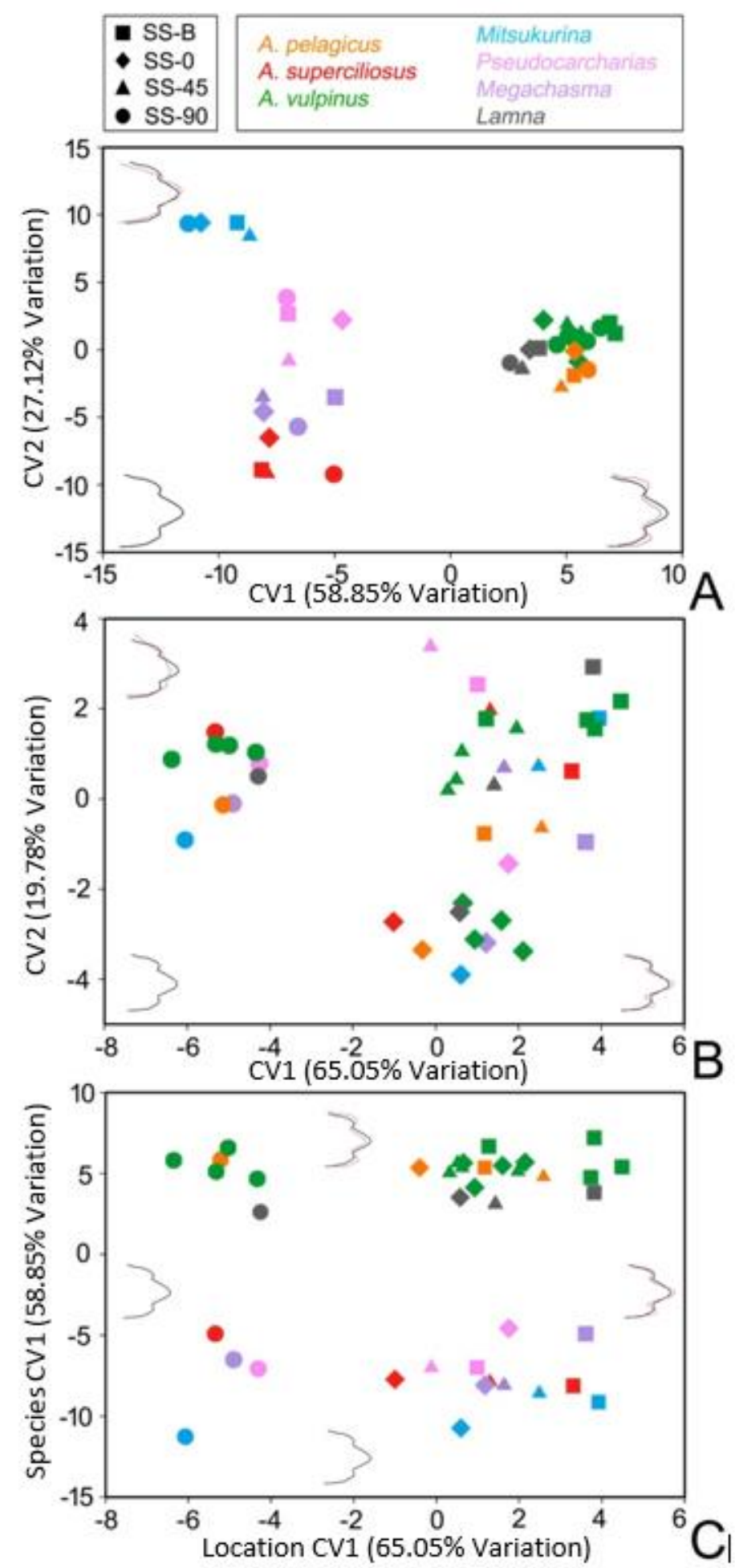

Figure 7. Graphs showing shape variation of placoid scales at four integument sampling sites in seven lamniform species examined grouped by species (A) and by integument sampling site (B) as well as by sampling site ('Location') and species (C) using canonical variate (CV) analysis. (see Appendices 5, 6). 


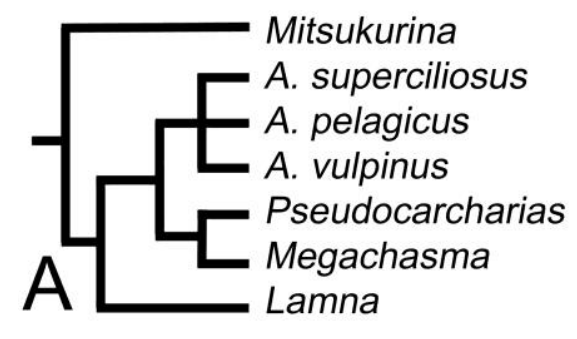

\begin{tabular}{llllllllll}
\multicolumn{3}{c}{ Scale density } & & & \multicolumn{3}{c}{ Average interkeel distance $(\mu \mathrm{m})$} \\
\cline { 1 - 5 } \cline { 6 - 8 } SS-B & SS-0 & SS-45 & SS-90 & & SS-B & SS-0 & SS-45 & SS-90 \\
13 & 21 & 16 & 16 & & 66.39 & 61.11 & 63.42 & 54.29 \\
52 & 135 & 201 & 276 & & 56.15 & 36.81 & 33.37 & 26.67 \\
132 & 184 & 155 & 214 & & 41.04 & 37.99 & 33.88 & 26.62 \\
98 & 110 & 172 & 214 & & 47.94 & 44.56 & 35.72 & 30.65 \\
47 & 58 & 72 & 68 & & 79.84 & 70.58 & 58.82 & 59.28 \\
27 & 50 & 34 & 58 & & 107.04 & 98.44 & 83.54 & 69.55 \\
72 & 55 & 49 & 82 & & 82.42 & 77.15 & 71.77 & 50.50 \\
& & & & & & & & & \\
13 & 21 & 16 & 16 & & 66.39 & 61.11 & 63.42 & 54.29 \\
47 & 58 & 72 & 68 & & 79.84 & 70.58 & 58.82 & 59.28 \\
27 & 50 & 34 & 58 & & 107.04 & 98.44 & 83.54 & 69.55 \\
52 & 135 & 201 & 276 & & 56.15 & 36.81 & 33.37 & 26.67 \\
132 & 184 & 155 & 214 & & 41.04 & 37.99 & 33.88 & 26.62 \\
98 & 110 & 172 & 214 & & 47.94 & 44.56 & 35.72 & 30.65 \\
72 & 55 & 49 & 82 & & 82.42 & 77.15 & 71.77 & 50.50
\end{tabular}

Figure 8. Scale density (* = per $2 \mathrm{~mm} \times 1.5 \mathrm{~mm}$ area) and average interkeel distances for each species examined mapped onto highly simplified (i.e., excluding non-examined taxa) molecularbased (A) and morphology-based (B) phylogenetic trees of the order Lamniformes ( $n=1$, except $n=4$ for Alopias vulpinus: see Appendices 1, 2). 
Appendix 1. Raw data of average interkeel distances (in $\mu \mathrm{m}$ ) for seven lamniform taxa examined ( $n=1$, except $n=4$ for Alopias vulpinus where standard deviation in parentheses).

\begin{tabular}{|l|l|l|l|l|l|l|l|}
\hline & $\begin{array}{l}\text { Alopias } \\
\text { pelagicus }\end{array}$ & $\begin{array}{l}\text { A. super- } \\
\text { ciliosus }\end{array}$ & A. vulpinus & $\begin{array}{l}\text { Mitsu- } \\
\text { kurina }\end{array}$ & $\begin{array}{l}\text { Pseudo- } \\
\text { carcharias }\end{array}$ & $\begin{array}{l}\text { Mega- } \\
\text { chasma }\end{array}$ & Lamna \\
\hline SS-B & 41.04 & 56.15 & $47.94( \pm 2.52)$ & 66.39 & 79.84 & 107.04 & 82.42 \\
\hline SS-0 & 37.99 & 36.81 & $44.57( \pm 2.46)$ & 61.11 & 70.58 & 98.44 & 77.15 \\
\hline SS-45 & 33.88 & 33.37 & $35.72( \pm 2.70)$ & 63.42 & 58.82 & 83.54 & 71.77 \\
\hline SS-90 & 26.62 & 26.67 & $30.65( \pm 1.11)$ & 54.29 & 59.28 & 69.55 & 50.50 \\
\hline
\end{tabular}


Appendix 2. Raw data of scale density per $2 \mathrm{~mm}$ x $1.5 \mathrm{~mm}$ area for seven lamniform taxa examined ( $n=1$, except $n=4$ for Alopias vulpinus where standard deviation in parentheses).

\begin{tabular}{|l|l|l|l|l|l|l|l|}
\hline & $\begin{array}{l}\text { Alopias } \\
\text { pelagicus }\end{array}$ & $\begin{array}{l}\text { A. super- } \\
\text { ciliosus }\end{array}$ & $\begin{array}{l}\text { A. } \\
\text { vulpinus }\end{array}$ & Mitsukurina & $\begin{array}{l}\text { Pseudo- } \\
\text { carcharias }\end{array}$ & Megachasma & Lamna \\
\hline SS-B & 132 & 52 & $98( \pm 45)$ & 13 & 47 & 27 & 72 \\
\hline SS-0 & 184 & 135 & $\begin{array}{l}110 \\
( \pm 37)\end{array}$ & 21 & 58 & 50 & 55 \\
\hline SS-45 & 155 & 201 & $\begin{array}{l}172 \\
( \pm 46)\end{array}$ & 16 & 72 & 34 & 49 \\
\hline SS-90 & 214 & 276 & $\begin{array}{l}214 \\
( \pm 20)\end{array}$ & 16 & 68 & 58 & 82 \\
\hline
\end{tabular}


Appendix 3. Raw dermis thickness measurements taken from seven lamniform taxa examined $(n=1)$.

\begin{tabular}{|l|l|l|}
\hline Species & SS-B & SS-45 \\
\hline Alopias pelagicus & 353.6 & 305.9 \\
\hline Alopias superciliosus & 450.8 & 161.8 \\
\hline Alopias vulpinus & 382.8 & 473.0 \\
\hline Mitsukurina & N/A & 239.7 \\
\hline Pseudocarcharias & N/A & 157.4 \\
\hline Megachasma & N/A & 262.8 \\
\hline Lamna & N/A & 342.3 \\
\hline
\end{tabular}


Appendix 4. Raw coordinate data for principle component analysis (PCA) on placoid scales.

\begin{tabular}{|c|c|c|c|c|c|c|}
\hline Id & specimen ID & species & Scale location & PCA 1 & PCA 2 & PCA 3 \\
\hline 1 & FMNH117473 & Alopias pelagicus & SS-B & -0.2397 & 0.0513 & -0.0260 \\
\hline 2 & FMNH117473 & Alopias pelagicus & SS-0 & -0.1619 & -0.0261 & 0.1332 \\
\hline 3 & FMNH117473 & Alopias pelagicus & SS-45 & -0.0739 & 0.0509 & 0.0348 \\
\hline 4 & FMNH117473 & Alopias pelagicus & SS-90 & 0.0558 & 0.0382 & -0.0837 \\
\hline 5 & FMNH117474 & Pseudocarcharias kamokari & SS-B & 0.0497 & -0.1016 & -0.0710 \\
\hline 6 & FMNH117474 & Pseudocarcharias kamokari & SS-0 & 0.0996 & -0.1016 & 0.0048 \\
\hline 7 & FMNH117474 & Pseudocarcharias kamokari & SS-45 & 0.1068 & -0.0735 & -0.0124 \\
\hline 8 & FMNH117474 & Pseudocarcharias kamokari & SS-90 & 0.2143 & 0.0369 & 0.0082 \\
\hline 9 & FMNH117475 & Lamna ditropis & SS-B & -0.3034 & -0.0210 & 0.0867 \\
\hline 10 & FMNH117475 & Lamna ditropis & SS-0 & -0.1821 & -0.1390 & -0.0356 \\
\hline 11 & FMNH117475 & Lamna ditropis & SS-45 & -0.2016 & -0.0069 & -0.0285 \\
\hline 12 & FMNH117475 & Lamna ditropis & SS-90 & -0.1608 & -0.0495 & -0.1435 \\
\hline 13 & FMNH117742 & Mitsukurina owstoni & SS-B & 0.3653 & 0.1272 & -0.0915 \\
\hline 14 & FMNH117742 & Mitsukurina owstoni & SS-0 & 0.3470 & -0.0245 & 0.1629 \\
\hline 15 & FMNH117742 & Mitsukurina owstoni & SS-45 & 0.3986 & 0.0457 & 0.1266 \\
\hline 16 & FMNH117742 & Mitsukurina owstoni & SS-90 & 0.3652 & -0.0151 & 0.0187 \\
\hline 17 & SIO0753 & Megachasma pelagios & SS-B & -0.0267 & -0.1417 & 0.0436 \\
\hline 18 & SIO0753 & Megachasma pelagios & SS-0 & 0.0454 & -0.1467 & 0.0060 \\
\hline 19 & SIO0753 & Megachasma pelagios & SS-45 & -0.0543 & -0.1384 & -0.0276 \\
\hline 20 & SIO0753 & Megachasma pelagios & SS-90 & 0.0014 & -0.2020 & -0.0131 \\
\hline 21 & SIO64804 & Alopias vulpinus & SS-B & -0.1876 & 0.0855 & 0.0272 \\
\hline 22 & SIO64804 & Alopias vulpinus & SS-0 & -0.1720 & 0.0067 & 0.2098 \\
\hline 23 & SIO64804 & Alopias vulpinus & SS-45 & -0.0152 & 0.1390 & 0.0212 \\
\hline 24 & SIO64804 & Alopias vulpinus & SS-90 & -0.0274 & -0.0107 & -0.1359 \\
\hline 25 & SI075379 & Alopias vulpinus & SS-B & -0.0881 & -0.0211 & 0.0204 \\
\hline 26 & SIO75379 & Alopias vulpinus & SS-0 & -0.0769 & 0.0368 & 0.0657 \\
\hline 27 & SIO75379 & Alopias vulpinus & SS-45 & -0.0363 & 0.1135 & -0.0463 \\
\hline 28 & SIO75379 & Alopias vulpinus & SS-90 & -0.0154 & 0.0885 & -0.0586 \\
\hline 29 & SIO78138A & Alopias vulpinus & SS-B & -0.0245 & -0.1061 & 0.0730 \\
\hline 30 & SIO78138A & Alopias vulpinus & SS-0 & -0.0080 & 0.1396 & 0.0923 \\
\hline 31 & SIO78138A & Alopias vulpinus & SS-45 & 0.0399 & -0.0028 & -0.1561 \\
\hline 32 & SIO78138A & Alopias vulpinus & SS-90 & 0.0027 & 0.1993 & -0.0643 \\
\hline 33 & SIO78138B & Alopias vulpinus & SS-B & -0.1677 & 0.0673 & 0.0847 \\
\hline 34 & SIO78138B & Alopias vulpinus & SS-0 & -0.1525 & 0.1402 & 0.0638 \\
\hline 35 & SIO78138B & Alopias vulpinus & SS-45 & 0.0125 & 0.0347 & 0.0707 \\
\hline 36 & SIO78138B & Alopias vulpinus & SS-90 & -0.0466 & 0.1364 & -0.1730 \\
\hline 37 & UF178509 & Alopias superciliosus & SS-B & 0.0457 & -0.1160 & -0.0368 \\
\hline 38 & UF178509 & Alopias superciliosus & SS-0 & 0.2398 & -0.0175 & 0.0041 \\
\hline 39 & UF178509 & Alopias superciliosus & SS-45 & 0.0542 & -0.0162 & -0.0175 \\
\hline 40 & UF178509 & Alopias superciliosus & SS-90 & -0.0211 & -0.0598 & -0.1369 \\
\hline
\end{tabular}


Appendix 5. Raw coordinate data for canonical variate (CV) analyses on placoid scales grouped by integument sampling sites ('Location').

\begin{tabular}{|c|c|c|c|c|}
\hline Id & Location & CV1 & CV2 & CV3 \\
\hline 0 & SS-B & 1.1614 & -0.8048 & 1.3495 \\
\hline 4 & SS-B & 1.0070 & 2.5335 & 0.8979 \\
\hline 8 & SS-B & 3.7928 & 2.8856 & 0.8021 \\
\hline 12 & SS-B & 3.9247 & 1.7731 & 1.9161 \\
\hline 16 & SS-B & 3.6377 & -0.9528 & 1.2354 \\
\hline 20 & SS-B & 3.8119 & 1.6044 & 1.4681 \\
\hline 24 & SS-B & 1.2679 & 1.8200 & 1.8696 \\
\hline 28 & SS-B & 3.7507 & 1.7459 & 2.4727 \\
\hline 32 & SS-B & 4.4756 & 2.1526 & 2.5215 \\
\hline 36 & SS-B & 3.2801 & 0.6136 & 2.8775 \\
\hline 1 & SS-0 & -0.3331 & -3.3555 & -0.6701 \\
\hline 5 & SS-0 & 1.7685 & -1.4602 & -0.5005 \\
\hline 9 & SS-0 & 0.5608 & -2.4725 & -0.1045 \\
\hline 13 & SS-0 & 0.5734 & -3.9086 & 0.7400 \\
\hline 17 & SS-0 & 1.1973 & -3.2036 & 1.5556 \\
\hline 21 & SS-0 & 2.1055 & -3.4290 & 1.0153 \\
\hline 25 & SS-0 & 0.9250 & -3.1441 & -0.0940 \\
\hline 29 & SS-0 & 1.6104 & -2.7546 & -0.1000 \\
\hline 33 & SS-0 & 0.6571 & -2.3336 & 0.8121 \\
\hline 37 & SS-0 & -1.0042 & -2.7106 & -1.4308 \\
\hline 2 & SS-45 & 2.5645 & -0.6316 & -2.0180 \\
\hline 6 & SS-45 & -0.1290 & 3.3550 & 0.1647 \\
\hline 10 & SS-45 & 1.4295 & 0.2846 & -1.7894 \\
\hline 14 & SS-45 & 2.4809 & 0.7518 & -4.0006 \\
\hline 18 & SS-45 & 1.6656 & 0.6974 & -2.6158 \\
\hline 22 & SS-45 & 0.3146 & 0.1936 & -2.2933 \\
\hline 26 & SS-45 & 0.6319 & 1.0647 & -3.0571 \\
\hline 30 & SS-45 & 1.9547 & 1.5322 & -3.1506 \\
\hline 34 & SS-45 & 0.5169 & 0.4350 & -2.7364 \\
\hline 38 & SS-45 & 1.3167 & 1.9540 & -1.7956 \\
\hline 3 & SS-90 & -5.1430 & -0.1295 & -0.0924 \\
\hline 7 & SS-90 & -4.2842 & 0.7786 & -1.7253 \\
\hline 11 & SS-90 & -4.2667 & 0.4717 & 1.9013 \\
\hline 15 & SS-90 & -6.0331 & -0.9441 & 1.9237 \\
\hline 19 & SS-90 & -4.8761 & -0.1208 & 0.4881 \\
\hline 23 & SS-90 & -4.3415 & 0.9759 & 0.9673 \\
\hline 27 & SS-90 & -5.0129 & 1.1971 & -0.0634 \\
\hline 31 & SS-90 & -6.3448 & 0.8450 & 1.4405 \\
\hline 35 & SS-90 & -5.3083 & 1.2231 & 0.8081 \\
\hline 39 & SS-90 & -5.3064 & 1.4674 & -0.9894 \\
\hline
\end{tabular}


Appendix 6. Raw coordinate data for canonical variate (CV) analysis on placoid scales grouped by species.

\begin{tabular}{|c|c|c|c|c|}
\hline Id & Species & CV1 & CV2 & CV3 \\
\hline 0 & A. pelagicus & 5.3012 & -1.8759 & 0.4323 \\
\hline 4 & P. kamokari & -7.0196 & 2.6927 & 2.6112 \\
\hline 8 & L. ditropis & 3.8075 & 0.0651 & 6.0653 \\
\hline 12 & M. owstoni & -9.1090 & 9.3621 & -0.7109 \\
\hline 16 & M. pelagios & -4.9407 & -3.4579 & 2.3193 \\
\hline 20 & A. vulpinus & 7.1310 & 1.2878 & -1.4062 \\
\hline 24 & A. vulpinus & 6.6841 & 1.7707 & 0.4263 \\
\hline 28 & A. vulpinus & 4.6898 & 0.5815 & -0.6785 \\
\hline 32 & A. vulpinus & 5.3807 & 0.9187 & -0.7389 \\
\hline 36 & A. superciliosus & -8.1319 & -8.8979 & -2.2464 \\
\hline 1 & A. pelagicus & 5.3196 & -0.1016 & -1.4014 \\
\hline 5 & P. kamokari & -4.6684 & 2.1240 & -1.8709 \\
\hline 9 & L. ditropis & 3.4216 & -0.0648 & 5.3704 \\
\hline 13 & M. owstoni & -10.7324 & 9.3213 & -0.0559 \\
\hline 17 & M. pelagios & -8.0802 & -4.5704 & 2.1781 \\
\hline 21 & A. vulpinus & 5.5458 & -0.9104 & -0.1429 \\
\hline 25 & A. vulpinus & 4.0547 & 2.1720 & -1.0020 \\
\hline 29 & A. vulpinus & 5.4843 & 0.9242 & -1.7589 \\
\hline 33 & A. vulpinus & 5.6375 & 0.6805 & -0.2512 \\
\hline 37 & A. superciliosus & -7.7490 & -6.6367 & -1.8142 \\
\hline 2 & A. pelagicus & 4.7535 & -2.7161 & -3.3849 \\
\hline 6 & P. kamokari & -6.9598 & -0.8472 & -0.1245 \\
\hline 10 & L. ditropis & 3.1092 & -1.4277 & 5.9633 \\
\hline 14 & M. owstoni & -8.6378 & 8.4622 & -1.3586 \\
\hline 18 & M. pelagios & -8.1067 & -3.5200 & 2.2752 \\
\hline 22 & A. vulpinus & 5.0114 & 1.8824 & -1.4465 \\
\hline 26 & A. vulpinus & 5.4040 & 0.7072 & -0.0482 \\
\hline 30 & A. vulpinus & 5.0827 & 1.0179 & -0.5062 \\
\hline 34 & A. vulpinus & 5.6248 & 1.1239 & -0.9607 \\
\hline 38 & A. superciliosus & -7.9541 & -9.1113 & -4.2714 \\
\hline 3 & A. pelagicus & 5.8654 & -1.5198 & -1.9658 \\
\hline 7 & P. kamokari & -7.0646 & 3.7040 & -1.4415 \\
\hline 11 & L. ditropis & 2.5782 & -1.0005 & 4.5463 \\
\hline 15 & M. owstoni & -11.2360 & 9.2213 & -0.4803 \\
\hline 19 & M. pelagios & -6.5793 & -5.7515 & 3.8614 \\
\hline 23 & A. vulpinus & 4.6130 & 0.4380 & -1.0538 \\
\hline 27 & A. vulpinus & 6.5081 & 1.6400 & -0.9296 \\
\hline 31 & A. vulpinus & 5.8108 & 0.6447 & -0.7407 \\
\hline 35 & A. vulpinus & 5.1353 & 0.9575 & -1.3132 \\
\hline 39 & A. superciliosus & -4.9847 & -9.2899 & -1.9453 \\
\hline
\end{tabular}

